\title{
Geocronología de los megadeslizamientos de Tenerife del último millón de años. Parte II. Nuevas aportaciones al conocimiento de los deslizamientos
}

\author{
Mercedes Ferrer Gijón ${ }^{(1)}$, Luis Ignacio González de Vallejo ${ }^{(2,3)}$ y Juan Carlos García López-Davalillo(1)
}

(1) Instituto Geológico y Minero de España. Área de Riesgos Geológicos. Ríos Rosas 23, 28003 Madrid.

(2) Universidad Complutense de Madrid. Dpto. de Geodinámica. José Antonio Novais 2, 28040 Madrid.

(3) Instituto Volcanológico de Canarias. 38320 San Cristóbal de La Laguna

m.ferrer@igme.es; vallejo@ucm.es; jc.garcia@igme.es

\begin{abstract}
RESUMEN
La revisión de las dataciones disponibles en la bibliografía relacionadas con los megadeslizamientos de la isla de Tenerife ocurridos en el último millón de años, y las nuevas dataciones Ar/Ar realizadas por los autores para acotar la edad de los mismos, han permitido proponer las siguientes edades para los deslizamientos de Icod: 170 ka; La Orotava: 560, 530 y 500(?) ka; Güímar: 830 ka; y Micheque: 810-830 ka (Ferrer et al., 2020-este volumen). En esta publicación se presentan las relaciones entre las evidencias geológicas y geomorfológicas indicadoras de los procesos de inestabilidad de los flancos, observadas tanto en superficie como en el interior de galerías que atraviesan los rellenos de los valles, y las edades de los deslizamientos. Se refuerza la hipótesis de la ocurrencia de varios deslizamientos de flanco superpuestos o solapados, espaciados en el tiempo, al menos, varias decenas de miles de años, descartándose la hipótesis de procesos únicos de rotura masiva e instantánea del flanco insular; así, en el caso del valle de La Orotava, se confirma una edad en torno a los 530 ka para un gran deslizamiento, y la ocurrencia de otros hacia los 560 ka y 500 ka. Se estudia también la relación y causalidad entre el deslizamiento de Icod, el último ocurrido en Tenerife, y la gran erupción explosiva del final del ciclo Cañadas, cuestión controvertida, y se demuestra que la explosión fue consecuencia del deslizamiento, desencadenada por éste hace $\sim 170 \mathrm{ka}$. Se presentan nuevas evidencias del deslizamiento de Micheque, y se aportan nuevos datos que indican una edad pliocena para el sustrato profundo de los deslizamientos de La Orotava y Micheque.
\end{abstract}

Palabras clave: Dataciones, Geocronología, Islas Canarias, Megadeslizamientos volcánicos, Tenerife.

\section{Geochronology of the mega-landslides of the last million years in Tenerife. Part II New contributions to knowledge about the landslides}

\begin{abstract}
The review on the ages available in the bibliography (1972-2019) related to the mega-landslides of the island of Tenerife in the last million years, and the new Ar/Ar ages we have obtained have allowed us to propose the following ages for the landslides of: Icod: 170 ka; La Orotava: 560, 530 y 500(?) ka; Güímar: 830 ka; and Micheque: 810-830 ka (Ferrer et al., 2020-this volume). The relationship between the ages of the landslides and the geological and geomorphological evidence that support the flank instability failure processes, based on field observations in outcrops and underground data -from the galleries excavated through the filling of the landslide valley-are presented. The hypothesis of several overlapping flank landslides, with time intervals of at least several tens of thousands of years is proposed, ruling out the occurrence of single processes of massive and instantaneous failure of the insular flank; thus, in the case of the La Orotava valley, an age of around $530 \mathrm{ka}$ is confirmed for a large landslide, as well as the occurrence of other landslides around $560 \mathrm{ka}$ and $500 \mathrm{ka}$. The relationship and causality between the lcod landslide, the last one that occurred in Tenerife, and the great explosive eruption at the end of the Cañadas cycle, and not the opposite as some authors have suggested, has also been analyzed, concluding that the explosion was a consequence of the landslide, 170 ka ago. New data and evidence for the Micheque landslide are shown, indicating a Pliocene age for the deep substrate of the La Orotava and Micheque landslides.
\end{abstract}

Keywords: age determinations, Canary Islands, geochronology, Tenerife, volcanic mega-landslides. 
M. Ferrer et al., 2020. Geocronología de los megadeslizamientos de Tenerife del último...Boletín Geológico y Minero, 131 (4): $941-970$

\section{ABRIDGED ENGLISH VERSION}

\section{Introduction}

Until now, the age of the mega-landslides of Tenerife during the last million years -lcod, La Orotava, Güímar and Micheque or Acentejo (Fig. 1)-, has been estimated from the ages of volcanic deposits, pre- or post landslide and chronologically related to them.

When assigning the age of the landslides, it has generally been assumed a large single catastrophic event was responsible for the dismantling of a flank of the volcanic edifice. However, as a result of submarine investigations of the landslide deposits off the northern coast of Tenerife, and other Canary islands, it has been suggested that the instability processes may occur in several multiple or recurrent landslides, based on morphological evidence of the submarine deposits (Watts y Masson, 1995; Ablay y Hurlimann, 2000), and their correlation with the subaerial features of the head escarps of some of the landslides (Biain et al., 2015; León et al., 2017).

Based on the review of the available literature data (1972-2019), and the new Ar/Ar age data obtained in galleries of the filling deposits of the landslide valleys of La Orotava, Güímar and Micheque (Ferrer et al., 2020this volume), the following representative ages for the landslides have been estimated: 165-175 ka for Icod, 560, 530 and 500(?) ka for La Orotava, $830 \mathrm{ka}$ for Güímar and 810-830 ka for Micheque (Tables 1 and 2). These results support the hypothesis of several overlapping landslides and not just a single event as was previously assumed.

On the contrary, a series of subaerial and submarine geological and geomorphological evidences suggest that the processes of dismantling the volcanic island flanks are due to a complex mechanism of the overlapping of large landslides (Figs. 2 and 3). Thus, it could be assumed that the most recent flank landslides in Tenerife have occurred in several different instability processes, and the morphological features of the current escarpments of the large valleys are the result of their superposition.

Some questions related to the age and the temporal occurrence of the instability processes of the flanks of Tenerife are presented and discussed. New evidence is provided to support the occurrence of several overlapping landslides on the flanks of the volcanic edifice, at least for some of the valleys. In the case of the La Orotava valley, the occurrence of three landslides is suggested, spaced by some tens of thousands of years.

\section{Data and discussion}

Geological evidence of overlapping landslides on the flanks of Tenerife

The main geological evidence that suggests the occurrence of several overlapping volcanic flank landslides is the following:

- The presence of different deposits of the landslide products, the so-called 'mortalón' (two or more) inside the galleries crossing through the fillings of the valleys.

- The morphological features of the landslide head scarps, showing several overlapping scars (Fig. 2).

- The morphological features of submarine proximal landslide deposits, showing differentiated events (Watts and Masson, 2001; Ablay and Hurlimann, 2000).

- Deposits of mega-tsunamis associated with the landslides of Tenerife, with different layers deposited by more than one tsunami, as reflected, for example, in the Agaete deposits, in Gran Canaria (Andrade et al., 2010; Madeira et al., 2011a).

The ages obtained for the different 'mortalon' deposits crossed by some of the galleries in the valleys of La Orotava and Guimar (Table 1), also provide evidence of the occurrence of several different landslides over time (Ferrer et al., 2020-this volume).

In the case of the La Orotava valley, the proposal of several overlapping landslides is based mainly on the ages obtained inside the galleries, and on the morphological features of the head scars of the landslides. In the Cruz de Luis and Bolaños galleries, ages between 500 and $530 \mathrm{ka}$, and between 506 and $528 \mathrm{ka}$, respectively, have been obtained, considering the uncertainties (Table 1 and Fig. 4). These ranges coincide with each other and with an age from the Pino Soler gallery (532 ka; Boulesteix et al., 2013). These data may suggest two possible landslides with time intervals of some tens of thousands of years, with ages around $\sim 500$ and $\sim 530 \mathrm{ka}$ (Ferrer et al., 2020-this volume). 
A conspicuous feature presented in La Orotava valley is the morphological step located in the centre of the valley (Fig. 2). This feature coincides in depth with a remarkable fracture and other related fault planes identified within the Bolaños gallery which could correspond to the head scarp of a large partial flank landslide (Figs. 4 and 5). This fracture has also been identified by a geochemical gas investigation carried out inside the Bolaños gallery (Melian, 2013) (Fig. 6). An age of 500 has been tentatively proposed for this escarpment, based on the age data obtained in rock samples from the Bolaños gallery (Ferrer et al., 2020-this volume); on the other hand, the filling materials of the La Orotava valley that appear in the Diego Hernández escarpment, in the Cañada de las Calderas, correspond the head area of the largest and main landslide in the valley ( 560 ka), whilst the current head scarp of the valley may possibly reflect a landslide towards $530 \mathrm{ka}$.

In the Güimar valley, age determinations have been carried out from rocks located inside the El Drago and Cueva de Las Colmenas galleries providing ages of 840 and 1,000 ka (Ferrer et al., 2020-this volume. This may suggest different landslides events. Subaerial and underground geological observations also suggest the occurrence of at least two large landslides; the morphological features of the head and lateral escarpments could reflect two landslides of similar magnitude (Figs. 4 and 5).

On the other hand, the tsunami deposits that appear in Agaete, NW of Gran Canaria, have been attributed to the Güímar landslide (Pérez-Torrado et al., 2006; Giachetti et al., 2011). These deposits present stratigraphic and sedimentological characteristics interpreted as three different tsunami events (Andrade et al., 2010; Madeira et al., 2011a).

Relationship between the Icod landslide and the explosive eruption of the end of the Cañadas cycle

The cause-effect relationship between the Icod landslide and the large explosive eruption culminating in the Cañadas volcanic cycle has been a much-debated issue in the literature, as it concerns the latest major 'catastrophic' event that destroyed the Cañadas III volcanic edifice. Here we present definitive evidence of the temporal relationship between the blast eruption and the large flank collapse of lcod. The mega-tsunami deposits associated with the Icod landslide, located on the north coast of Tenerife, show two clearly differentiated layers. The lower layer can be attributed to the tsunami event caused by the landslide, whilst the upper layer can be assigned to the tsunami waves caused by the violent entry into the sea of the blast-lateral explosive eruptionproducts, triggered immediately after the landslide.

Although in the case of lcod both events are associated, flank mega-landslides on volcanic islands do not necessarily have to be triggered by, or associated with, a large explosive eruption. The main factors determining flank stability conditions are the height of the volcanic edifices and the physical and mechanical properties of the underwater materials that form the basement of the island and support its weight: the hyaloclastites (Oehler et al., 2005; Schiffman et al., 2006; Ferrer et al., 2010 and 2015).

\section{The underlying substratum of the landslides}

In Cruz de Luis gallery sited in La Orotava valley, the landslide substratum underlying the deepest 'mortalón' deposit has been dated at $2.55 \mathrm{Ma}$ (Ferrer et al., 2020-this volume). The difference of 2 Ma with the age of the lava flows overlying the 'mortalón' deposit ( 0.5 Ma), could suggest that the materials deposited after the first large landslide would have been cut and dragged by the second one. An age of 1.32 Ma has also been obtained for a dike in an intensely altered and fractured section in the Las Breñas gallery, which implies a greater age for the lava flows into which the dike intrudes.

From the new Ar/Ar age determinations (Table 1), it can be deduced that the substratum of the landslides is only represented by a deposit dated 2.5 Ma reached in the Cruz de Luis gallery, in La Orotava valley; the other age data from deposits underlying the 'mortalón', with ages around 500-530 ka, would represent valley filling deposits.

\section{Conclusions}

New evidence and age data are presented that support the hypothesis of several large overlapping landslides, spaced in time, to explain the instability processes of the flanks of the island of Tenerife: (i) The presence of 
different deposits of 'mortalón' inside the galleries; (ii) The new age determinations of the 'mortalón' deposits; (iii) The morphological features of the landslide head scarps, and other morphological features; and (iv) The structure of the mega-tsunami deposits attributed to the Güimar landslide. For La Orotava valley, three overlapping landslides are proposed, tentatively dated at 560, 530 and 500 ka. In Güímar valley, two large slides can be suggested, with an imprecise age of between 0.8 and $1 \mathrm{Ma}$; there is no definitive evidence for the Icod and Micheque valleys, as their main morphological features remain buried and insufficient age determinations of the underground deposits of 'mortalon' are available so far.

Regarding the causal relationship between the landslide and the final explosive eruption (blast) of the last cycle of the Cañadas edifice, both 170 ka ago, the evidence suggests that the landslide occurred immediately before the eruption, as some authors have postulated, although without conclusive evidence so far. The main evidence is provided by the mega-tsunami deposits associated with both events laying on the north coast of Tenerife, with two clearly differentiated layers, without time interval between them, whose characteristics allow the basal layers to be attributed to the landslide tsunami and the upper layer to the blast triggered immediately after the landslide.

The new ages here provided for rocks underlying the landslide deposits ('mortalón'), correspond to the substratum of the La Orotava and Micheque landslides, through which the failure/landslide surfaces were developed: $2.55 \mathrm{Ma}$ for a lava flow, and 1.32 Ma for a dike in an intensely altered and fractured section, which implies a greater age for the lava flows into which the dike intrudes. From the data it can be deduced that the landslides dragged the pleistocene deposits, exposing the oldest materials of the so-called NE Dorsal Range, which would be partially covered by the rock landslide deposits, and later buried by post-landslide volcanism lava flows.

\section{Introducción}

Los megadeslizamientos de los flancos insulares de Tenerife han suscitado el interés científico desde que, en los años 60 y 70 del pasado siglo, se plantease la teoría de las grandes avalanchas rocosas para explicar el controvertido origen de los valles de La Orotava y Güímar, y posteriormente de la depresión de Las Cañadas (Bravo, 1962; Coello, 1973), a raíz del descubrimiento de unos depósitos brechoides en el fondo de las galerías excavadas en las laderas del norte de la isla para abastecimiento de agua, interpretados en su día como el plano de despegue de los deslizamientos. Pero no fue hasta finales de los años 80 del pasado siglo, con los trabajos de Coello y Bravo (1989) y Navarro y Coello (1989) cuando esta hipótesis es aceptada e incorporada, en adelante, a los estudios sobre la historia y evolución geológicas de la isla (Ancochea et al., 1990; Carracedo, 1994, entre otros).

El conocimiento actual de la geología de Tenerife, permite afirmar que los deslizamientos de Icod, La Orotava y Güímar, junto con el denominado de Acentejo o Micheque (Carracedo et al., 2009) o East Dorsal (Ablay and Hurlimann, 2000), éste sin reflejo morfológico en superficie, han ocurrido en el último millón de años, condicionando las últimas fases de la evolución geológica de la isla, de unos 12 a $15 \mathrm{Ma}$ de antigüedad (Ancochea et al., 1990; Hernández Pacheco y Rodríguez Losada, 1996; Carracedo et al., 2007).

Actualmente, destacan en el relieve de la isla los grandes escarpes laterales de cientos de metros de altura de los valles de La Orotava y Güimar, que son, junto con la Caldera de Las Cañadas y el pico Teide, de $3.715 \mathrm{~m}$ de altura, los accidentes morfológicos más emblemáticos de Tenerife. En el caso del deslizamiento de Icod y el de Micheque, los valles han sido cubiertos totalmente por cientos de metros de coladas, enmascarando los escarpes y cicatrices de las roturas de los flancos de los edificios volcánicos (Figura 1).

Estos deslizamientos se encuentran entre los mayores movimientos de ladera del planeta, con volúmenes de las masas subaéreas deslizadas estimadas entre los 50 y $100 \mathrm{~km}^{3}$, y representan violentas fases destructivas en la evolución de los edificios volcánicos, no siempre asociadas a grandes erupciones explosivas.

El hecho de que sean procesos prehistóricos de magnitud a escala geológica, incomparable con la de otros procesos de inestabilidad de laderas, incluso considerando los mayores deslizamientos subaéreos registrados en la Tierra -como el del volcán Santa Helena, EE.UU. en 1980, con un volumen de $2,8 \mathrm{~km}^{3}-$ hacen difícil y complejo su estudio, quedando muchas cuestiones por resolver sobre el desarrollo y los mecanismos de las rotura de los flancos volcánicos, sus tipologías y profundidad, por no citar las causas de los megadeslizamientos, tema objeto de controversia y sobre el que existe un gran desconocimiento.

Uno de los aspectos relevantes es conocer la edad de los deslizamientos, lo que permite ordenar la historia geológica de la isla deTenerife y establecer relaciones con otros procesos volcánicos, además de proporcionar información sobre los factores geológicos que controlan el desarrollo de estos grandes movimientos de masas y su recurrencia, y sobre otros posibles efec- 


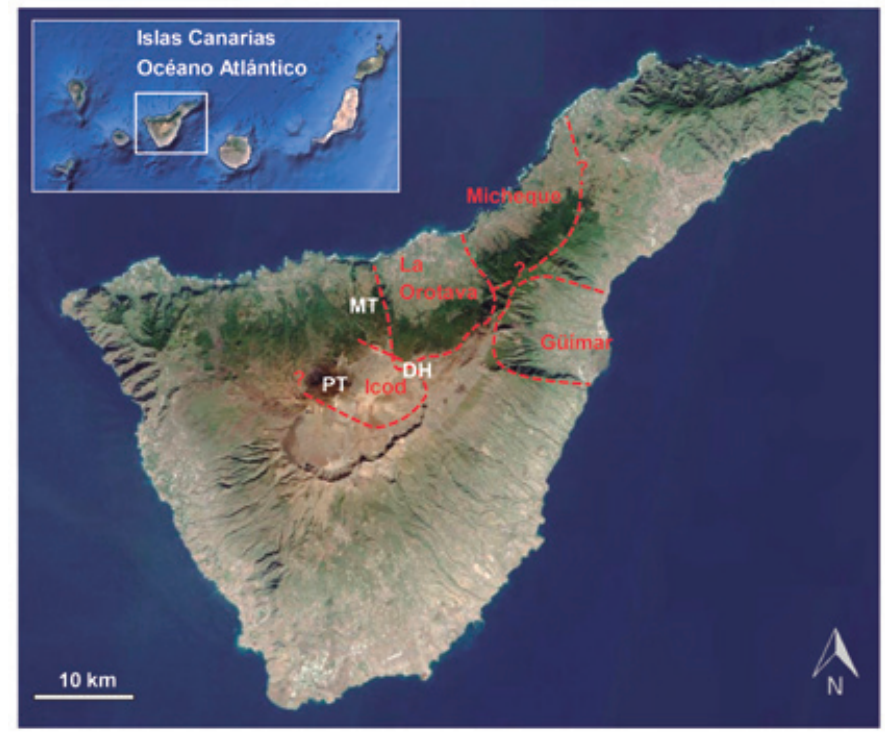

Figura 1. Representación esquemática de los límites de los deslizamientos más recientes de Tenerife: Icod, La Orotava, Güímar y Micheque o Acentejo. DH: pared de Diego Hernández en la Caldera de Las Cañadas; MT: Macizo de Tigaiga; PT: Pico Teide. Los límites del deslizamiento de Micheque según Carracedo et al. (2011). Mapa base: GRAFCAN.

Figure 1. Schematic representation of the most recent landslides in Tenerife: Icod, La Orotava, Guímar and Micheque or Acentejo. DH: Diego Hernández wall in Las Cañadas Caldera; MT: Tigaiga Massif; CM: Cho Marcial volcano; PT: Teide Peak. Limits of Micheque landslide from Carracedo et al. (2011). Basemap: GRAFCAN.

tos asociados, como los tsunamis causados por la entrada violenta de las enormes avalanchas rocosas en el océano.

Hasta ahora, la edad de los deslizamientos se ha estimado, con mayor o menor grado de certidumbre, a partir de dataciones de depósitos relacionados con ellos, previos o posteriores, realizadas en numerosos trabajos sobre la geología de Tenerife, desde el pionero de Abdel Monem et al. (1972). Con los datos disponibles, en ocasiones muy escasos, y las relaciones cronoestratigráficas, se han asignado edades, o rangos de edades, a los diferentes deslizamientos, siempre considerando un único episodio catastrófico como responsable de la formación de los valles.

Sin embargo, y a raíz de las investigaciones submarinas de los depósitos deslizados de la costa norte de Tenerife, y posteriormente en los flancos de otras islas como La Palma y El Hierro, se ha planteado la idea de que los procesos de inestabilidad ocurren en varios episodios, varios deslizamientos múltiples o recurrentes, por las evidencias morfológicas de los depósitos submarinos (Watts y Masson, 1995; Urgeles et al., 1999; Ablay y Hurlimann, 2000) y su correlación con los rasgos subaéreos de los escarpes de cabecera de algunos de ellos (Biain et al., 2015; León et al., 2017).

Ante este planteamiento, no es consecuente asumir a priori un único episodio y una única edad para los deslizamientos, al menos para todos ellos.

Ferrer et al. (2020-este volumen), en un trabajo sobre la edad de los deslizamientos del último millón de años en Tenerife, llevan a cabo una revisión detallada de las dataciones disponibles en la bibliografía (19722019), y presentan una serie de nuevas dataciones $\mathrm{Ar} /$ Ar realizadas en el interior de galerías que atraviesan los rellenos de los valles deslizados, con la finalidad de aportar nuevos datos para conocer la edad de los deslizamientos de La Orotava, Güímar y Micheque. La interpretación de las dataciones, apoyada con datos de campo, ha conducido a conclusiones que refuerzan la propuesta de varios deslizamientos superpuestos sobre un mismo flanco volcánico. En el caso de La Orotava, se propone la ocurrencia de tres deslizamientos superpuestos, que finalmente configuraron el gran valle actual, espaciados en el tiempo unas decenas de miles de años.

En la presente publicación se presentan y discuten, a la luz de los resultados de las nuevas dataciones $\mathrm{Ar} /$ Ar realizadas por los autores, y de observaciones realizadas en las galerías y otros trabajos de campo, algunas cuestiones de interés relacionadas con la edad y pautas de ocurrencia de los procesos de inestabilidad de los flancos de Tenerife.

Se aportan nuevas evidencias geológicas y geomorfológicas que apoyan la ocurrencia de varios deslizamientos superpuestos o solapados para explicar el desmantelamiento de los flancos del edificio volcánico, al menos en algunos de los valles de Tenerife.

Como resultado de los trabajos llevados a cabo, se plantea también una cuestión estrechamente relacionada con la edad y el desarrollo de los procesos de inestabilidad de los flancos volcánicos, como es la relación causa-efecto entre el deslizamiento de Icod y la gran erupción explosiva con que culminó el último ciclo eruptivo del Edificio Cañadas, cuestión sobre la que diferentes autores no se ponen de acuerdo, a pesar de haber sido un tema muy debatido dada la cercanía en el tiempo de estos conspicuos procesos geológicos y el interés que su estudio ha despertado al tratarse de los últimos grandes acontecimientos 'catastróficos' que destruyeron el gran, y anterior al actual, edificio volcánico Cañadas III.

Se aportan nuevos datos y evidencias sobre el deslizamiento de Micheque, el menos conocido e investigado de los más recientes ocurridos en Tenerife (último millón de años), y sobre la edad del sustrato profundo de los deslizamientos de Micheque y La Orotava, aspectos poco investigados de los megadeslizamientos de Tenerife, dada la inaccesibilidad a depósitos y materiales enterrados bajo cientos de metros de coladas, tanto en el caso del deslizamiento de Micheque como en lo que se refiere a los sustratos de los 
deslizamientos, formados por materiales antiguos de la Dorsal noreste cuyo flanco norte fue desmantelado por ambos deslizamientos.

La presente publicación es complementaria de la citada anteriormente (Ferrer et al., 2020-este volumen), que constituye la primera parte (Parte I) del trabajo sobre la edad de los deslizamientos de Tenerife llevado a cabo por los autores.

\section{Las edades de los delizamientos}

En Ferrer et al. (2020-este volumen) se lleva a cabo una revisión detallada de las dataciones disponibles en la bibliografía hasta 2019 relacionadas con los cuatro deslizamientos de la isla de Tenerife ocurridos en el último millón de años -Icod, La Orotava, Güímar y Micheque o Acentejo-, estimándose sus edades más representativas. Las dataciones, publicadas a partir de los años 90 del pasado siglo, exceptuando las pioneras de Abdel Monem et al. (1972), corresponden a depósitos pre o postdeslizamiento relacionados cronoestratigráficamente con los deslizamientos:

- Depósitos de los escarpes de deslizamiento y otros posteriores a los deslizamientos sobre los escarpes de Icod, La Orotava y Güímar (Abdel Monem et al., 1972; Ancochea et al., 1990; Martí et al., 1990; Ibarrola et al., 1993; Mitjavila y Villa, 1993; Brown et al., 2003; Carracedo et al., 2009 y 2011; Edgar et al., 2007; Boulesteix et al., 2012 y 2013).

- Materiales de relleno y depósitos posteriores a los deslizamientos de La Orotava, Güímar y Micheque (Abdel Monem et al., 1972; Ancochea et al., 1990; Ibarrola et al., 1993; Carracedo et al., 2009).

- Rocas en el interior de galerías de Icod, La Orotava y Micheque (Carracedo et al., 2006 y 2009; Boulesteix et al., 2012 y 2013).

- Datación de depósitos submarinos de turbiditas asociadas a los deslizamientos de Icod, La Orotava y Güímar (Frenz et al., 2009; Hunt et al., 2013a).

De los autores citados, solo Boulesteix et al. (2013) ha realizado dataciones exprofeso para conocer la edad del deslizamiento de La Orotava. Es de destacar también la escasez de dataciones (5) en galerías que pueden ser empleadas para estimar la edad de los deslizamientos.

Igualmente, Ferrer et al. (2020-este volumen) presentan los resultados de una serie de nuevas dataciones $\mathrm{Ar} / \mathrm{Ar}$ realizadas por los autores con la finalidad de acotar la edad de los deslizamientos de La Orotava, Güímary Micheque. Las dataciones se han realizado en rocas del interior de galerías que atraviesan los rellenos de los valles deslizados y los depósitos dejados por los deslizamientos en el fondo de los mismos, denomina- dos con el término 'mortalón' (una brecha caótica con cantos y bloques polimícticos y heterométricos englobados en matriz limoarcillosa). Varias de las muestras datadas corresponden a coladas situadas a muro de los depósitos de deslizamiento, lo que supone una aportación destacable, ya que hasta ahora únicamente se contaba con una datación en estos materiales del sustrato, en una galería del valle de Micheque (Carracedo et al., 2009). Así mismo, se han datado por primera vez rocas procedentes de las galerías del valle de Güímar.

En laTabla 1 se presentan los resultados de las nuevas dataciones; la Tabla 2 muestra las edades deducidas para los deslizamientos a partir de éstas y las estimadas a partir de las dataciones bibliográficas.

Del análisis de las dataciones bibliográficas y las propias se han estimado las edades más representativas para los deslizamientos: 165-175 ka para Icod, $\sim 560, \sim 530$ y $\sim 500$ (?) ka para La Orotava, $\sim 830$ ka para Güímar y 810-830 ka para Micheque. En el caso del valle de La Orotava se han deducido tres posibles deslizamientos superpuestos con edades diferentes (Ferrer et al., 2020-este volumen); en los casos de Güímar y Micheque, las dataciones existentes no permiten confirmar la ocurrencia de varios deslizamientos.

\section{Sobre la ocurrencia de deslizamientos superpuestos a la luz de las nuevas dataciones Ar/Ar y de las eviden- cias geológicas}

Hasta ahora, cuando se han tratado en la literatura aspectos relacionados con la edad de los deslizamientos deTenerife, se ha considerado, sin otros planteamientos, que se trata de movimientos gravitacionales muy rápidos de grandes masas rocosas que, de una sola vez, desmantelan una gran parte del edificio volcánico, incluyendo su cumbre y parte del flanco sumergido; esta premisa, en general, no ha sido discutida por los autores que han tratado la edad de los grandes deslizamientos de Canarias; de esta forma, las dataciones disponibles se han interpretado con el objetivo de acotar una edad concreta para cada uno de los cataclismos ocurridos en Tenerife, sin entrar en consideraciones sobre la génesis, desarrollo o mecanismos de rotura de las inestabilidades de flanco.

Sin embargo, una serie de evidencias geológicas subaéreas y submarinas, puestas en consideración e integradas bajo un enfoque global, indican que estos procesos de desmantelamiento de los flancos volcánicos no tienen lugar de manera tan simple, y apuntan a la ocurrencia de deslizamientos complejos, superpuestos o, cuando menos, con varios movimientos de reajuste de grandes masas rocosas, espaciados en el tiempo, tras cada una de las grandes roturas iniciales. 


\begin{tabular}{|c|c|c|c|}
\hline Deslizamiento & Muestra & Situación y nombre de la galería & Edad (ka) \\
\hline \multirow{8}{*}{ La Orotava } & CLU -2312 & Muro del 'mortalón' 2, Crü de Luis & $2.556 \pm 52$ \\
\hline & $\mathrm{CLU}-2275$ & Techo del 'mortalón' 2, Crù de Luis & $470 \pm 41$ \\
\hline & $\mathrm{CLU}-1380$ & Muro del 'mortalón' 1, Cru\% de Luis & $506 \pm 26$ \\
\hline & CLU - 1312 & Techo del 'mortalón' 1, Cruy de Luis & $498 \pm 24$ \\
\hline & $\mathrm{BOL}-1141$ & Muro del 'mortalón', Bolaños & $510 \pm 18$ \\
\hline & $\mathrm{BOL}-0979$ & Techo del 'mortalón', Bolaños & $537 \pm 31$ \\
\hline & $\mathrm{TI}-0002$ & Escarpe de Tigaiga & $664 \pm 38$ \\
\hline & DAT $-3 *$ & $\begin{array}{l}\text { Techo 'mortalón' I, Pasada de } \\
\text { Montelongo }\end{array}$ & $341 \pm 17$ \\
\hline \multirow{4}{*}{ Güímar } & $\mathrm{CCO}-2215$ & Techo 'mortalón', Cueva de las Colmenas & $835 \pm 30$ \\
\hline & $\mathrm{GU}-0001$ & Escarpe de Güimar & $799 \pm 25$ \\
\hline & $\mathrm{DAT}-2^{*}$ & Techo del ‘mortalón' 2, El Drago & $\begin{array}{l}990 \pm 40 \\
(1.140 \pm 50)\end{array}$ \\
\hline & DAT $-1^{*}$ & Techo 'mortalón', Cueva de Las Colmenas & $\begin{array}{l}1.130 \pm 70 \\
(1.090 \pm 50)\end{array}$ \\
\hline \multirow[t]{2}{*}{ Micheque } & LBR -5350 & Muro del 'mortalón', Las Breñas & $1.320 \pm 140$ \\
\hline & LBR -4963 & Techo del 'mortalón', Las Breñas & $808 \pm 31$ \\
\hline
\end{tabular}

Tabla 1. Dataciones Ar/Ar llevadas a cabo en rocas procedentes de galerías y escarpes de La Orotava, Güímar y Micheque. Table 1. Ar/Ar ages of rocks from galleries and landslide scarps of La Orotava, Güímar and Micheque valleys.

Así, podría asumirse que los deslizamientos de flanco más recientes de Tenerife, los de Icod, La Orotava y Güímar, se han producido en varios y diferenciados procesos de inestabilidad, siendo los rasgos morfológicos de los escarpes que configuran los grandes valles de la isla el resultado de la superposición de los distintos procesos.

Los estudios submarinos más recientes de los depósitos deslizados sobre el flanco norte de la isla de Tenerife, han proporcionado, hasta ahora, los principales argumentos para proponer la existencia de deslizamientos múltiples o recurrentes en base a la diferenciación morfológica de varios lóbulos en los depósitos asociados a los diferentes grandes deslizamientos (Ablay and Hurlimann, 2000; Watts and Masson, 2001), aunque sin llegar a establecer relaciones espaciales o temporales con los procesos de inestabilidad.

Ante las anteriores consideraciones, no es consecuente asumir una única edad para cada uno de los deslizamientos, tal como se ha venido haciendo hasta ahora, con las subsiguientes discrepancias a la hora de ajustar los datos disponibles, sobre todo en los casos en que se dispone de un mayor número de dataciones representativas para datar un deslizamiento.

El análisis detallado de las dataciones existentes y las nuevas dataciones aportadas por los autores (Ferrer et al., 2020-este volumen) permiten proponer la ocurrencia de varios movimientos superpuestos diferenciados en el tiempo, con posibles intervalos de algunas decenas de miles de años, como se concluye en el trabajo citado para el caso del valle de La Orotava. Este planteamiento de los procesos de inestabilidad de los flancos de las grandes islas volcánicas permite interpretar las dataciones en otro contexto, pero, al mismo tiempo, supone una mayor complejidad y recurrencia de los procesos de inestabilidad y, por tanto, mayor dificultad para su datación y para establecer los límites temporales de los distintos deslizamientos superpuestos. 


\begin{tabular}{|c|c|c|c|c|c|}
\hline \multicolumn{5}{|c|}{$\begin{array}{l}\text { Deslizamiento, depósitos datados y sus edades, y edad deducida para el } \\
\text { deslizamiento de la revisión bibliográfica de las dataciones }\end{array}$} & $\begin{array}{l}\text { Edad según } \\
\text { este trabajo }\end{array}$ \\
\hline \multirow[t]{4}{*}{ Icod } & \multirow[t]{3}{*}{$\begin{array}{l}\text { Depósitos } \\
\text { volcánicos } \\
\text { subaéreos }\end{array}$} & $\begin{array}{l}\text { Niveles superiores del escarpe } \\
\text { de cabecera del deslizamiento } \\
\text { (pared de Diego Hernánde } \% \text { ) }\end{array}$ & $173-183 \mathrm{ka}$ & \multirow{4}{*}{$\begin{array}{l}\sim 165-175 \mathrm{ka}^{1} \\
160-180 \mathrm{ka}^{2}\end{array}$} & \multirow{4}{*}{ - } \\
\hline & & $\begin{array}{l}\text { Depósitos asociados } \\
\text { temporalmente al deslizamiento } \\
\text { (unidad El Abrigo) }\end{array}$ & $130-196 \mathrm{ka}$ & & \\
\hline & & $\begin{array}{l}\text { Relleno del valle dejado por el } \\
\text { deslizamiento }\end{array}$ & $161-198 \mathrm{ka}$ & & \\
\hline & \multicolumn{2}{|c|}{$\begin{array}{l}\text { Turbiditas submarinas profundas procedentes } \\
\text { del deslizamiento }\end{array}$} & $160-200 \mathrm{ka}$ & & \\
\hline \multirow[t]{4}{*}{$\begin{array}{l}\text { La } \\
\text { Orotava }\end{array}$} & \multirow[t]{3}{*}{$\begin{array}{l}\text { Depósitos } \\
\text { subaćreos }\end{array}$} & $\begin{array}{l}\text { Niveles superiores del escarpe } \\
\text { Este }\end{array}$ & $560-566 \mathrm{ka}$ & \multirow{3}{*}{$\sim 560 \mathrm{ka}$} & \multirow{4}{*}{$\begin{array}{l}510-530 \mathrm{ka} \\
\sim 500 \mathrm{ka}^{5}\end{array}$} \\
\hline & & $\begin{array}{l}\text { Niveles superiores del escarpe } \\
\text { Oeste y Maci } / 0 \\
\text { de Tigaiga }\end{array}$ & $549 / 560 \mathrm{ka}$ & & \\
\hline & & $\begin{array}{l}\text { Relleno del valle dejado } \\
\text { por el deslizamiento }\end{array}$ & $540-730 \mathrm{ka}$ & & \\
\hline & \multicolumn{2}{|c|}{$\begin{array}{l}\text { Turbiditas submarinas profundas procedentes } \\
\text { del deslizamiento (Llanura Abisal de } \\
\text { Madeira) }\end{array}$} & $500-540 \mathrm{ka}$ & $\sim 535 \mathrm{ka}^{3}$ & \\
\hline \multirow[t]{2}{*}{ Güimar } & \multicolumn{2}{|c|}{$\begin{array}{l}\text { Depósitos subaéreos de los escarpes y de } \\
\text { relleno del valle }\end{array}$} & $830-860 \mathrm{ka}$ & \multirow{2}{*}{$\begin{array}{c}-830 \mathrm{ka}^{4} \\
830-840 \mathrm{ka}^{1}\end{array}$} & \multirow{2}{*}{$\sim 830 \mathrm{ka}$} \\
\hline & \multicolumn{2}{|c|}{$\begin{array}{l}\text { Turbiditas submarinas profundas procedentes } \\
\text { del deslizamiento }\end{array}$} & $830-850 \mathrm{ka}$ & & \\
\hline $\begin{array}{l}\text { Micheque } \\
\text { o } \\
\text { Acentejo }\end{array}$ & \multicolumn{2}{|c|}{$\begin{array}{l}\text { Depósitos subaćreos de los escarpes y de } \\
\text { relleno del valle }\end{array}$} & $560-830 \mathrm{ka}$ & $\geq 830 \mathrm{ka}$ & $\begin{array}{l}>808 \mathrm{ka} \\
<1.320 \mathrm{ka}\end{array}$ \\
\hline \multicolumn{6}{|c|}{$\begin{array}{l}1 \text { Considerando las dataciones más representativas tanto de rocas subaćreas como de sedimentos submarin } \\
{ }^{2} \text { Considerando solo las edades de los depósitos directamente relacionados con el deslizamiento: niveles } \\
\text { del escarpe y relleno temprano del valle. } \\
{ }^{3} \text { Boulexteix et al. (2013) estiman una edad similar, entorno a los } \sim 530 \mathrm{ka} \text { con dos dataciones subaéreas. } \\
{ }^{4} \text { Considerando las dataciones más representativas de rocas subaćreas. } \\
{ }^{5} \text { Considerando las dataciones del nivel de mortalón menos profundo de la Galeria Cru/ de Luis. }\end{array}$} \\
\hline
\end{tabular}

Tabla 2. Edades de los deslizamientos deducidas de las dataciones bibliográficas y edades estimadas según nuevas dataciones Ar/Ar en rocas de galerías.

Table 2. Ages of the landslides deduced from data in the literature, and ages estimated according to new Ar/Ar data of rocks from the galleries.

NOTA: Estas consideraciones no se refieren a deslizamientos ocurridos en un mismo flanco del edificio volcánico con diferencia de cientos de miles de años, afectando a diferentes grandes edificios que crecen sucesivamente, como los ocurridos en el flanco norte del edificio Cañadas, al menos tres en los últimos 1,5 Ma (Watts and Masson, 1995; Cantagrel et al., 1999; An- cochea et al., 1999), que han conformado los distintos sectores del escarpe de la Caldera de las Cañadas, sino que se trataría de un gran deslizamiento inicial y uno o varios posteriores, igualmente de gran tamaño, ocurridos sobre el mismo flanco del mismo edificio, probablemente por desequilibrio tras la gran rotura inicial, y separados en el tiempo unas decenas de miles de años. 


\section{Evidencias geológicas de deslizamientos superpues- tos en los flancos de Tenerife}

Las principales evidencias geológicas que apuntan a la ocurrencia de varios o múltiples deslizamientos de flanco volcánico superpuestos solapados son las siguientes:

- Presencia de dos o más paquetes o niveles de 'mortalón', claramente diferenciables, en el interior de las galerías, como se ha constatado en algunas de ellas visitadas por los autores en los valles de La Orotava y Güímar. Efectivamente, las observaciones geológicas en el interior de las galerías que atraviesan los flancos deslizados de los edificios volcánicos, con los trabajos pioneros de Bravo (1962) y Coello (1973), han puesto de manifiesto la presencia de varias capas o paquetes diferenciados de 'mortalón' (la brecha que representa los depósitos dejados por los deslizamientos sobre las superficies de rotura) bajo las coladas de relleno de los valles. Estos datos apuntan a la posible ocurrencia de varios deslizamientos superpuestos espaciados en el tiempo, o de procesos de reajuste gravitatorio de las masas rocosas y de los propios depósitos de 'mortalón', posteriores al movimiento principal, al quedar el flanco en condiciones de estabilidad precaria.

- Rasgos morfológicos en las cabeceras de los grandes valles dejados por los deslizamientos, que indican o sugieren cicatrices de varios procesos, como en el escarpe de cabecera del valle de La Orotava (Figura 2), o, de forma muy clara, los que se dibujan en el escarpe del deslizamiento de El Golfo, en la isla de El Hierro (Figura 3), el más reciente megadeslizamiento de las islas Canarias; en ambos casos se identifican deslizamientos superpuestos (Cantagrel et al., 1999; Biaín et al., 2015; León et al., 2017). En el valle de Güímar, el escarpe de cabecera refleja dos grandes lóbulos, más amplio y desdibujado el situado al norte (Figura 2).

- Rasgos morfológicos submarinos: lóbulos super-

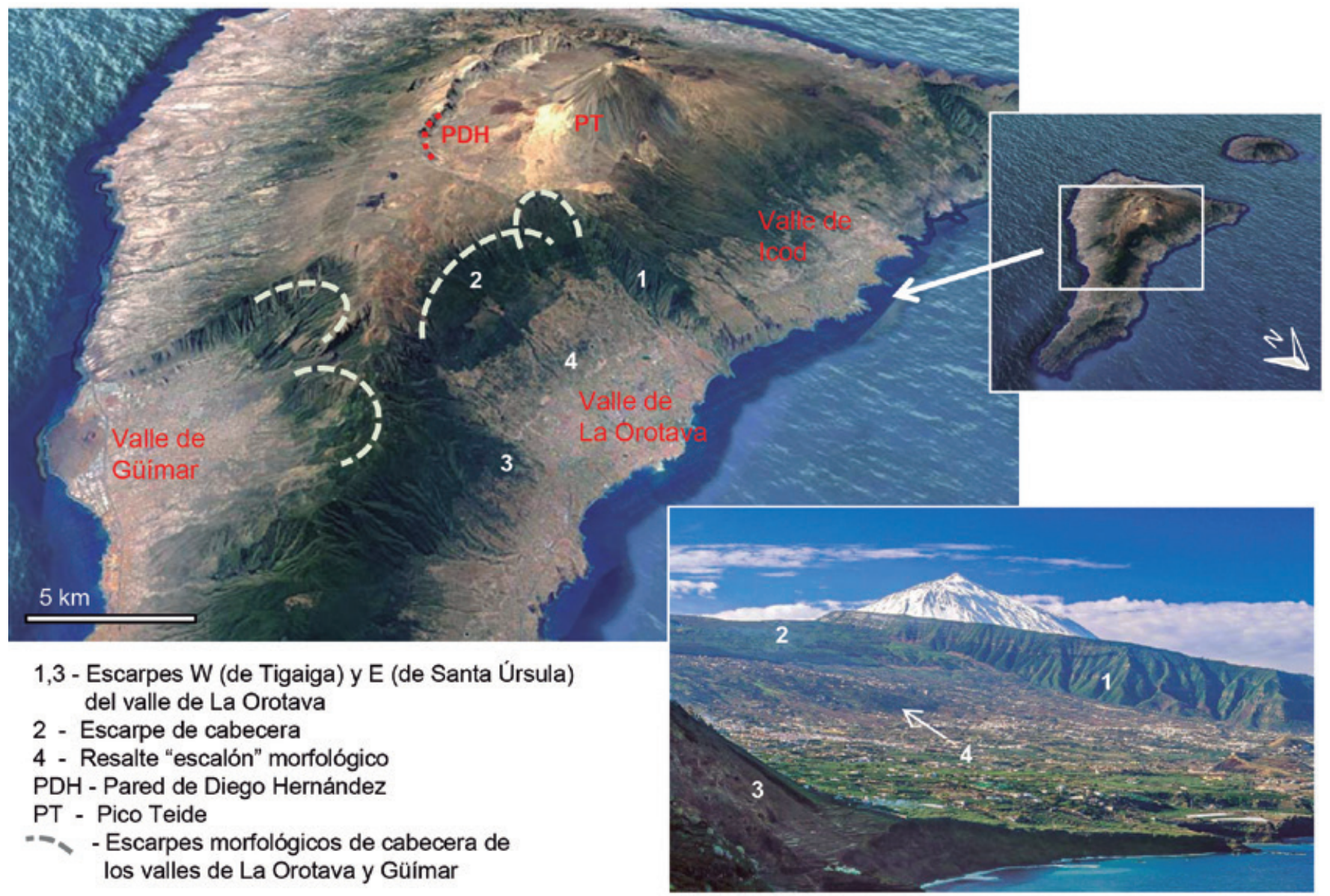

Figura 2. Vista aérea de los valles de La Orotava y Güímar, con los rasgos morfológicos actuales que marcan sus escarpes de cabecera. Mapa base: Google Earth. Fotografía inferior derecha: valle de La Orotava visto desde el noreste, con su marcado escarpe oeste (escarpe deTigaiga, de hasta $600 \mathrm{~m}$ de altura) y el destacado resalte morfológico que presenta hacia la cota 500.

Figure 2. Aerial view of the valleys of La Orotava and Güimar, with the current head scarps morphological features. Base map: Google Earth. Lower right photograph: La Orotava valley seen from the northeast, with its marked west escarpment (Tigaiga escarpment, up to 600 $m$ high) and the outstanding morphological step that appears towards level 500. 


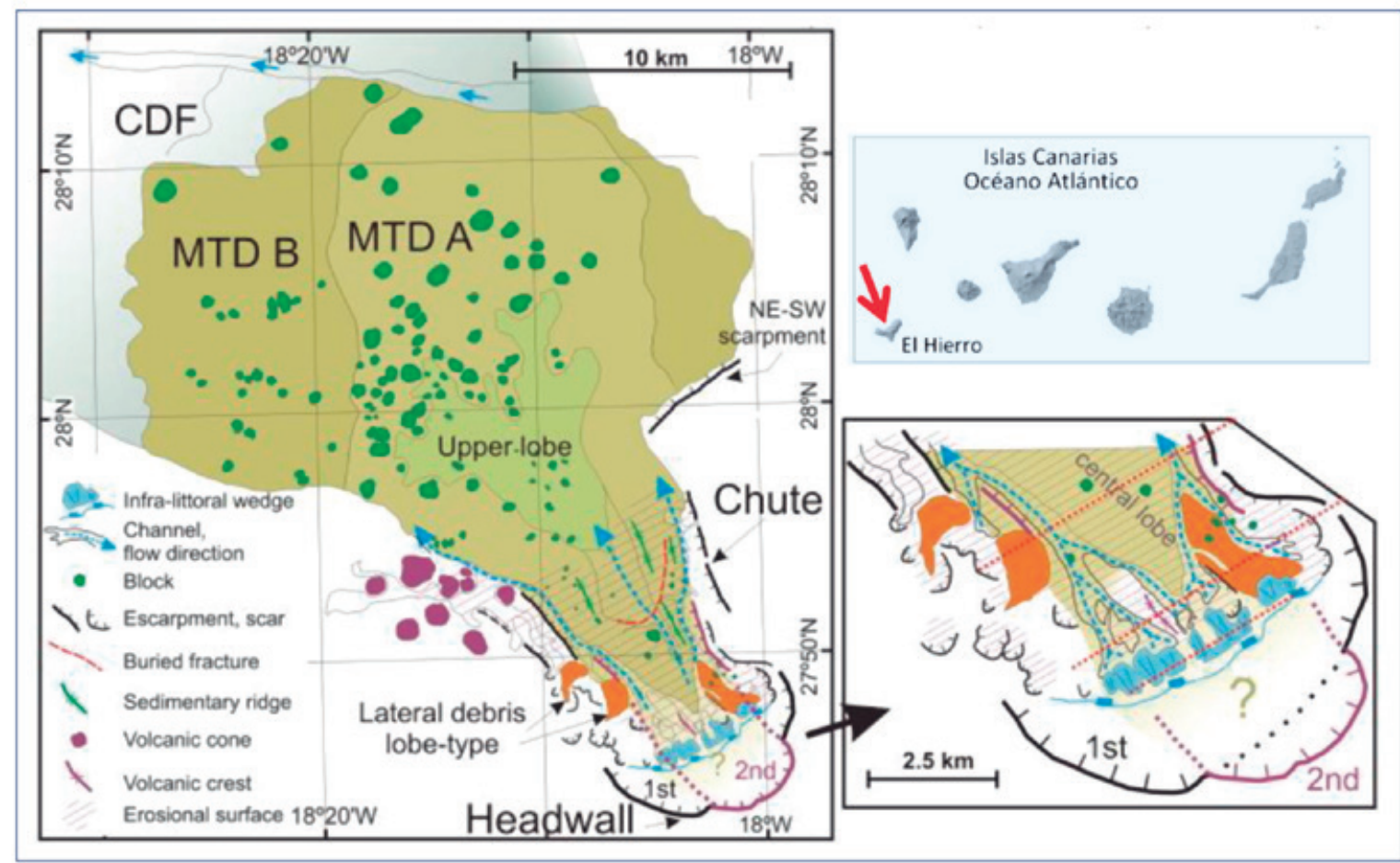

Figura 3. Interpretación geomorfológica del deslizamiento de El Golfo (en la isla de El Hierro) mostrando las principales características. En los escarpes de cabecera del deslizamiento (Headwall) se dibujan dos lóbulos diferentes de rotura (ver detalle en el cuadro inferior derecho); MTD A y MTD B son dos grandes depósitos de avalanchas de derrubios diferenciados; CDF son depósitos de flujo de derrubios. Estos deslizamientos son los más recientes ocurridos en Canarias, por lo que sus rasgos morfológicos subaéreos y submarinos denotan claramente la ocurrencia de deslizamientos superpuestos. (Modificado de León et al., 2017).

Figure 3. Geomorphological interpretation of the El Golfo landslide (El Hierro island) showing the headwall scarps of the landslide with two different lobes (see detail in lower right box); MTD A and MTD B: debris avalanche deposits; CDF: debris flow deposits. These landslides are the most recent in the Canary Islands, and its subaerial and submarine morphological features clearly denote the occurrence of overlapping landslides. (Modified from León et al., 2017).

puestos en los depósitos sumergidos proximales de los deslizamientos (depósitos de las avalanchas de rocas que penetran en el mar), como han puesto de manifiesto Watts and Masson (2001) para el deslizamiento de Icod, distinguiendo dos depósitos, Icod I e Icod II, suficientemente diferenciados para sugerir que corresponden a procesos diferentes. También Ablay and Hurlimann (2000) deducen la ocurrencia de múltiples deslizamientos en los casos de Icod, La Orotava y el denominado Dorsal Este, a partir del análisis morfológico de los depósitos submarinos de los deslizamientos, que se extienden hasta $70 \mathrm{~km}$ de distancia de la costa: 3 lóbulos diferenciados en el caso de Icod y 2 para La Orotava y Dorsal Este. León et al. (2017) cartografían dos grandes depósitos submarinos diferenciados correspondientes al deslizamiento de El Golfo, que asocian a los dos episodios que se reflejan en los escarpes de cabecera (Figura 3).

- Algunos depósitos de los megatsunamis asociados a los deslizamientos de Tenerife muestran varias capas depositadas por más de un tsunami, como se refleja, por ejemplo, en los depósitos de Agaete, en Gran Canaria (Andrade et al., 2010; Madeira et al., 2011a); en la revisión de campo llevada a cabo en el sitio por los autores citados, se han diferenciado depósitos de hasta 3 tsunamis, apuntando sin duda a diferentes deslizamientos. Los depósitos de tsunami de Agaete han sido tentativamente asociados al deslizamiento de Güímar (Pérez-Torrado et al., 2006; Giachetti et al., 2011). Evidencias de depósitos fósiles de tsunamis asociados a megadeslizamientos prehistóricos, con capas depositadas por múltiples tsumanis, se han descrito también en las islas Hawaii (Felton et al., 2000; Rubin et al., 2000).

A partir de las anteriores evidencias puede sustentarse la hipótesis de la ocurrencia de varios deslizamientos en un mismo flanco diferenciados en el tiempo. Estos procesos complejos comenzarían con un gran deslizamiento por rotura del flanco submarino, que se lleva gran parte del flanco emergido, e incluso la cumbre del edificio, y posteriormente tendrían lugar otras roturas de flanco probablemente de menor envergadura. Así, los deslizamientos "secundarios" pueden afectar a masas rocosas más allá de los límites de la rotura inicial, a los propios depósitos dejados por el deslizamiento inicial y a nuevos materiales deposi- 
tados en los valles tras la rotura, y ocurrir con lapsos de tiempo de varias decenas de miles de años entre ellos. Estos deslizamientos "secundarios" serían también capaces de arrastrar grandes volúmenes de rocas hacia el mar.

Este escenario de deslizamientos superpuestos permite una mayor "flexibilidad" para interpretar las dataciones realizadas en el interior de las galerías en los valles de La Orotava y Güímar (Ferrer et al., 2020este volumen), pero también una mayor complejidad de los procesos y mecanismos de inestabilidad de los flancos volcánicos de Tenerife. A la luz de estas consideraciones pueden explicarse también algunas de las diferencias $\mathrm{o}$ incongruencias en las dataciones publicadas empleadas para estimar las edades de los diferentes deslizamientos de Tenerife, tal como se recoge en Ferrer et al. (2020-este volumen).

\section{Valle de La Orotava}

Una de las características de muchas de las galerías excavadas en el valle de La Orotava es la presencia de dos o más tramos de depósitos de 'mortalón', como ocurre, entre otras, en las galerías Cruz de Luis, Pasada de Montelongo y Pino Soler, visitadas por los autores (ver situación en la Figura 4). Los distintos tramos de 'mortalón' que aparecen en estas galerías excavadas en la parte alta y cabecera del valle están separados por capas de coladas y escorias con diques, más o menos fracturadas y alteradas, de hasta varios cientos de metros a lo largo de las galerías. Estos distintos paquetes de 'mortalón', que representan los depósitos residuales de las grandes masas rocosas deslizadas y destruidas durante su caída, podrían interpretarse de forma diferente:

- Corresponden a diferentes deslizamientos espaciados en el tiempo, al menos unos miles o decenas de miles de años, sobre todo si aparecen separados por paquetes potentes de coladas; de ellos, el más importante sería el más profundo, que representaría al primer y principal deslizamiento.

- Corresponden a diferentes movimientos o etapas dentro del mismo deslizamiento y pueden considerarse contemporáneos a efectos geológicos, aunque pueden haberse dado depósitos de coladas entre ellos; los depósitos de 'mortalón' más superficiales corresponderían a movimientos gravitacionales locales de reajuste del equilibrio de las masas rotas tras el deslizamiento principal, masas rocosas trasportadas o depósitos coluviales procedentes de los depósitos in situ del 'mortalón'.

- Corresponden a la misma capa de 'mortalón', bien por presentar ésta "ondulaciones" al adaptarse a la orografía irregular del terreno tras el deslizamiento, o bien porque el trazado de la galería corte al mismo depósito de 'mortalón' más de una vez.

Estas hipótesis podrían quedar reflejadas en las galerías del valle de La Orotava citadas anteriormente. Si se considera la primera hipótesis puede deducirse el carácter múltiple de los deslizamientos de flanco volcánico, como por otro lado cada vez más evidencias geológicas indican, siendo el producto del deslizamiento más antiguo, y probablemente el de mayor magnitud, el 'mortalón' más profundo. En el caso segundo, el 'mortalón' principal sería el más profundo, y el paquete o paquetes que aparecen por encima no proporcionarían datos significativos sobre la edad del deslizamiento principal o primero, excepto en el caso de cortos lapsos de tiempo entre el depósito de los diferentes 'mortalones'. Es decir, cuando en las galerías se atraviesan dos o más depósitos de 'mortalón', éstos pueden corresponder a dos diferentes deslizamientos espaciados en el tiempo o reflejar distintas etapas de inestabilidad del mismo proceso. En las galerías que atraviesan solo un depósito de 'mortalón', descartando que haya otro más profundo, éste podría corresponder a uno u otros de los deslizamientos ocurridos sobre el flanco volcánico, dependiendo de la 'historia' de los procesos de inestabilidad y de la situación y cotas de la galería.

En algunas de las galerías visitadas en el valle de La Orotava se observan criterios que permiten establecer si el 'mortalón' corresponde al depósito original in situ del deslizamiento, por ejemplo, por la presencia de coladas y materiales alterados y fracturados a su base, incluso planos de fractura importantes y zonas brechificadas de potencias considerables, o por la presencia de planos de fractura destacados que podrían corresponder a las zonas de rotura y escarpes del deslizamiento. Esto se ha observado en la galería Bolaños, a la que más adelante se hace referencia, y en la galería Pino Soler, donde los últimos cientos de metros excavados, a muro del segundo tramo de 'mortalón', presentan una intensa fracturación y alteración, con una red de diques muy intensa, destacando la presencia de planos de fractura.

Como se explica en detalle en la publicación que constituye la Parte I complementaria del presente estudio (Ferrer et al., 2020-este volumen), en el apartado sobre las nuevas dataciones $\mathrm{Ar} / \mathrm{Ar}$, las edades obtenidas para las muestras de la galería Cruz de Luis por encima del paquete de 'mortalón' más profundo (Tabla 1 y Figura 4) (ver Tabla 6 y Figura 10 en Ferrer et al., 2020-este volumen, para detalles) pueden situarse en conjunto en torno a los 510-530 ka, considerando las incertidumbres. Las observaciones realizadas en la galería no permiten asegurar que el 


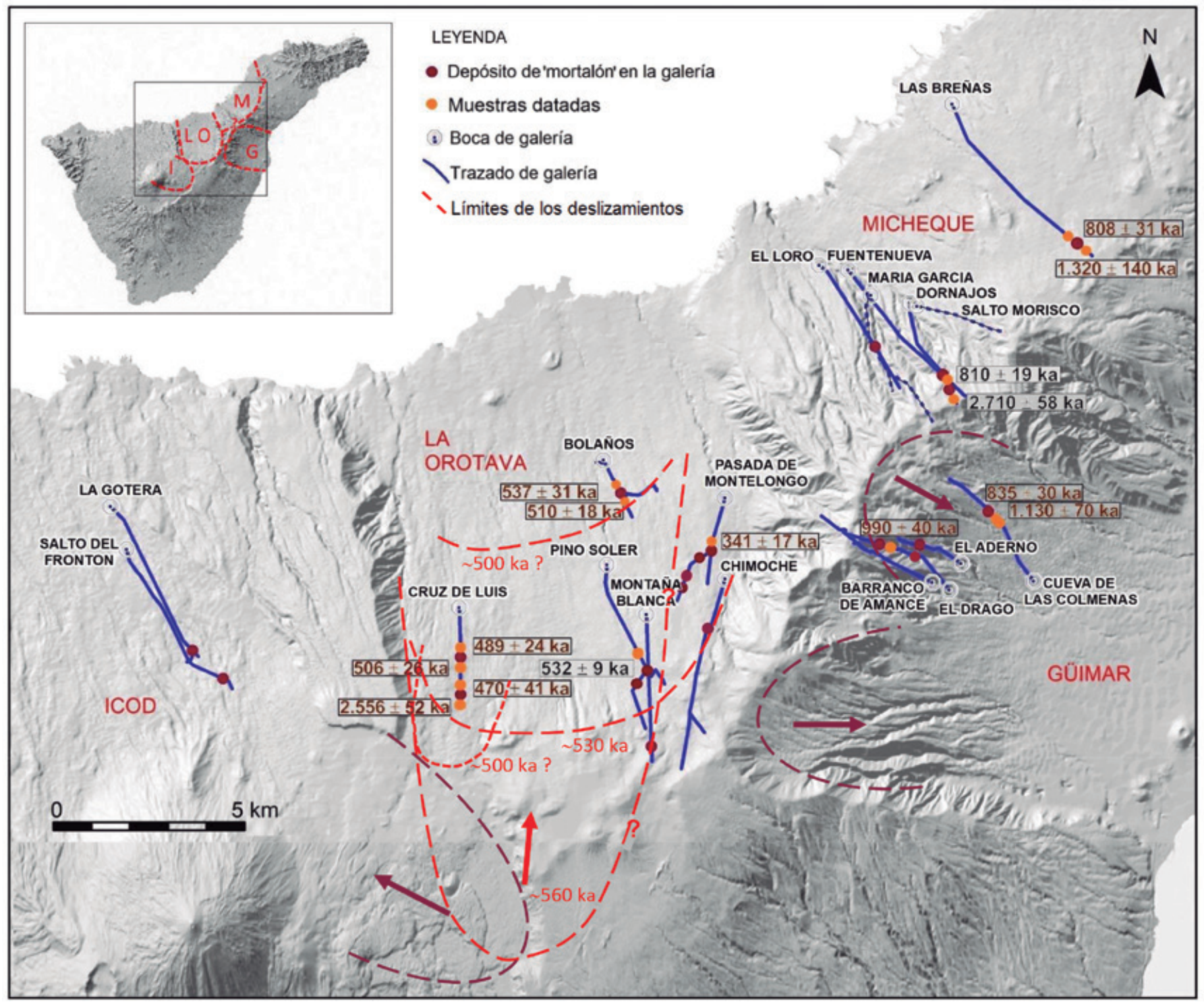

Figura 4. Situación de las galerías que se citan en el texto en los valles de La Orotava, Güímar, Micheque e Icod, y representación de los límites de los deslizamientos propuestos del valle de La Orotava (línea discontinua roja), Güímar e lcod (línea morada); se indican las edades posibles para los deslizamientos de La Orotava. Sobre cada galería se han marcado los puntos donde aparecen los depósitos de 'mortalón' referidos en el texto, y las dataciones realizadas por los autores; en los casos de las galerías Dornajos (Micheque) y Pino Soler (La Orotava) las edades se han tomado de Carracedo et al. (2009) y Boulesteix et al. (2013) respectivamente. Las galerías Salto Morisco y María García, en la zona de Micheque, marcadas con línea de puntos, se incluyen únicamente a efectos de localización. Los límites de los deslizamientos se han trazado en base a rasgos morfológicos y evidencias geológicas (ver explicaciones en el texto). Mapa base: GRAFCAN. Datos de trazado de las galerías: CIATF (2019).

Figure 4. Location of the galleries quoted in the text in the valleys of La Orotava, Güímar, Micheque and Icod, and representation of the limits of the proposed landslides on the La Orotava valley (red dashed line), Güímar and Icod (purple line); the possible ages proposed for the La Orotava landslides are indicated. The points where the deposits of 'mortalón' referred to in the text appear, and the age determinations by the authors, have been marked on each gallery; in the cases of Dornajos and Pino Soler galleries, the ages have been taken from Carracedo et al. (2009) and Boulesteix et al. (2013) respectively. The Salto Morisco and María García galleries, in the Micheque area, marked with a dotted line, are included for location purposes only. The limits of the landslides have been drawn based on morphological features and geological evidence (see explanations in the text). Basemap: GRAFCAN. Gallery layout data: CIATF.

'mortalón' menos profundo sea "autóctono", ya que a muro aparece una colada sin alterar (donde se ha realizado una datación de $506 \pm 26 \mathrm{ka}$, Tabla 1), que podría indicar que el contacto no corresponde a un plano de deslizamiento, sino que el depósito habría sido transportado posteriormente a la rotura. Otra hipótesis a considerar en esta galería, es que los dos depósitos de 'mortalón' correspondan a deslizamientos diferentes, entre los 500 y $530 \mathrm{ka}$, espaciados en el tiempo unos miles o decenas de miles de años, pudiendo sugerirse una edad en torno a los 500 ka para el primero, y de 510-530 ka para el más profundo, jugando con las incertidumbres de las dataciones (Ferrer et al., 2020-este volumen). De hecho, el depósito 


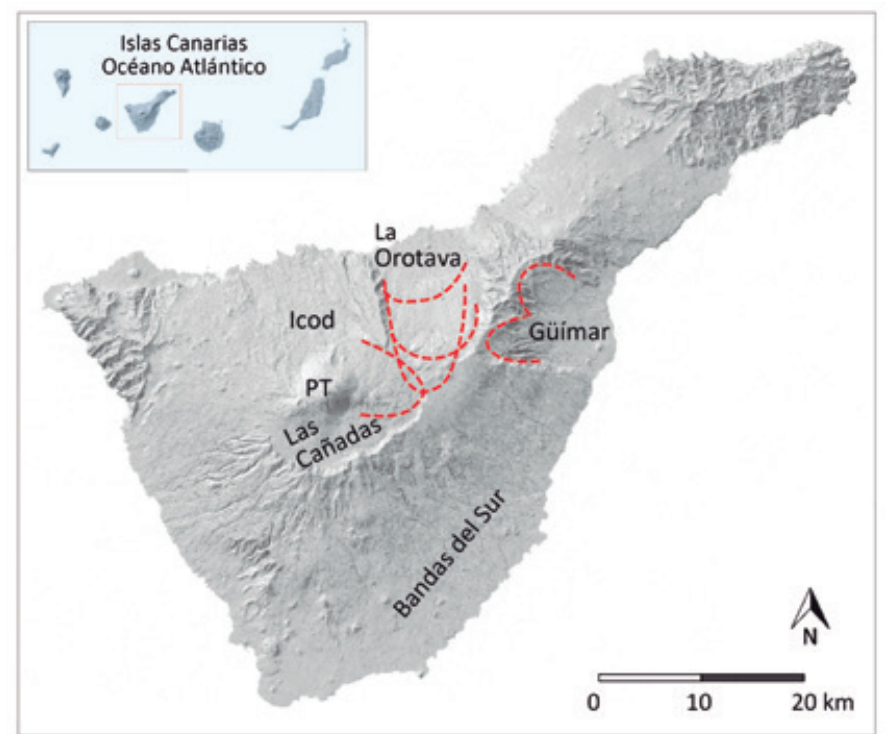

Figura 5. Representación esquemática de las cabeceras de los posibles deslizamientos superpuestos en los valles de La Orotava y Güímar, y de la cabecera del deslizamiento de Icod. Mapa base: GRAFCAN.

Figure 5. Schematic representation of the head scarps of proposed overlapping landslides in the La Orotava and Güímar valleys, and the head scarp of the Icod landslide. Basemap: GRAFCAN.

de 'mortalón' más superficial podría corresponder a un deslizamiento menor cuyo escarpe de cabecera se refleja al suroeste de la cabecera actual del valle de La Orotava (Figura 4), asignándole tentativamente una edad de $\sim 500 \mathrm{ka}$, mientras que el más profundo podría representar el deslizamiento general del valle en torno a los $530 \mathrm{ka}$.

No obstante, con la información disponible, a priori no puede descartarse ninguna de las anteriores interpretaciones para explicar la presencia de los dos paquetes de 'mortalón' en el interior de la galería Cruz de Luis.

En el caso de la galería Pasada de Montelongo, con un ramal de más de 3.000 m de longitud, excavada en la pared oriental del valle (ver situación en Figura 4), se atraviesan cuatro tramos de 'mortalón', de unos pocos metros el primero, algo más de $100 \mathrm{~m}$ el segundo y varios cientos de metros el tercero y el cuarto, separados entre sí unos 100,500 y 100 m respectivamente. La edad obtenida para la colada de techo del 'mortalón' más cercano a bocamina, 341 ka (Tabla 1), así como las observaciones in situ, permiten suponer que se trata de un depósito diferente, más moderno, de los otros tramos más profundos y potentes de 'mortalón', y con posible origen en un deslizamiento posterior a los principales. El más profundo y potente tramo de 'mortalón' atravesado por la galería aparece hacia los $2.630 \mathrm{~m}$, a $1.200 \mathrm{~m}$ de distancia del primero, hecho que apoya la hipótesis de que se trata de depósitos muy diferentes. Por tanto, la edad de 341 ka podría corresponder a un último deslizamiento parcial ocurrido en el valle, o a un movimiento local de reajuste de las masas rocosas, mientras que los otros paquetes más antiguos podrían representar a uno o dos deslizamientos más antiguos, hacia los 530 y 560(?) ka. La falta de más datos sobre la edad de los paquetes de 'mortalón' que aparecen en esta galería impide deducciones más precisas.

Un indicio a favor de la hipótesis de varios grandes deslizamientos superpuestos en el valle de La Orotava es el "escalón" o resalte morfológico que se observa a partir de la cota 500 aproximadamente, en el centro del valle, con dirección transversal al mismo (Figura 2). Este destacable rasgo morfológico coincide con la localización en profundidad de una zona con fracturas y planos de falla, atravesada por la galería Bolaños, situada en la zona central del valle con entrada a la cota 485 m (ver Figuras 4), y refleja una adaptación del relieve a un probable escarpe de rotura enterrado bajo las coladas de relleno del valle, que correspondería al escarpe de cabecera de un gran deslizamiento parcial del flanco (en la Figura 4 y en el esquema de la Figura 5 se indica la situación de este escarpe). Este desnivel topográfico lo reflejan también las isolíneas de profundidad del techo de los depósitos de 'mortalón' que tapizan el fondo del valle de La Orotava, como muestran los perfiles longitudinales del valle (Coello y Bravo, 1989; Seisdedos, 2009); en los perfiles se observa también que la sucesión de coladas de lava que han ido rellenando el valle sobre los depósitos basales de 'mortalón' aumenta de forma muy considerable y brusca a partir del desnivel-escarpe hacia la cabecera del valle actual, llegando a los $700 \mathrm{~m}$, mientras que es mucho más reducido (100-150 m) entre el resalte y la zona baja del valle hasta el mar (Figura 6d), quizás denotando la falta del material deslizado, que habría sido arrastrado al mar por el deslizamiento con cabecera hacia la cota 500 o 600 actual.

La presencia de una fractura en profundidad en esta zona del valle de La Orotava se refleja de forma muy clara en las mediciones de gases llevadas a cabo en el interior de la galería Bolaños (Melian, 2013), trabajos realizados exprofeso para la investigación de la fractura. Los resultados evidencian que se produce un cambio significativo en las relaciones molares $\mathrm{H}_{2} / \mathrm{Ar} y$ $\mathrm{CO}_{2} / \mathrm{O}_{2}$, entre otras, reflejando un incremento de gases de origen profundo a favor de dicha falla/fractura (Figura 6).

El primer depósito de 'mortalón' en la galería Bolaños aparece hacia los $980 \mathrm{~m}$ de bocamina, con una longitud de unos $160 \mathrm{~m}$ en el ramal oeste (con dirección NNW-SSE); bajo el mismo aparecen coladas de 
lava intercaladas con materiales sedimentarios y coluviones situados sobre la fractura-escarpe.

Las dataciones realizadas a techo y muro de este depósito de 'mortalón', dan una edad entre 506 y 528 ka (ver Tabla 6 y explicaciones en el texto en Ferrer et al., 2020-este volumen), en el mismo rango de la edad del 'mortalón' de la galería Cruz de Luis (510-530 ka) y de la galería Pino Soler (>532 ka; Boulesteix et al., 2013); estos datos pueden indicar que se trata de depósitos del mismo deslizamiento, en torno a los 530 ka, o depósitos de diferentes deslizamientos con edades posibles sobre los $\sim 500$ y los $\sim 530 \mathrm{ka}$.

Las evidencias geológicas en superficie y en el interior de las galerías permiten proponer la ocurrencia de varios grandes deslizamientos superpuestos en el valle de La Orotava. Las nuevas dataciones realizadas por los autores (Tabla 1) refuerzan esta hipótesis, sin descartar que no hayan tenido lugar otros deslizamientos menores dentro del valle. En el Apartado de discusión se desarrolla y explica esta propuesta.

\section{Valle de Güímar}

En el valle de Güímar, la escasez de dataciones disponibles para estimar su edad, no permite la propuesta de varios deslizamientos. Además, su mayor antigüedad ha hecho que los rasgos morfológicos de los escarpes estén muy erosionados y desdibujados. No obstante, se incluyen a continuación algunas consideraciones sobre los datos y dataciones obtenidas del interior de las galerías.

La galería El Drago, en la cabecera de la parte central del valle (Figura 4) corta dos extensos tramos de 'mortalón', de varios cientos de metros cada uno y separados entre sí casi $400 \mathrm{~m}$, que podrían corresponder a deslizamientos diferentes, dada su distancia. En esta galería se cuenta con una datación a techo del 'mortalón' más profundo, a unos $2.300 \mathrm{~m}$ de bocamina (Tabla 1) de $\sim 1 \mathrm{Ma}$, pudiendo asignar esta edad al deslizamiento profundo.

En la galería Cueva de Las Colmenas, a menor cota que la anterior y hacia el norte, aparece un único tramo de 'mortalón' de más de $150 \mathrm{~m}$ de longitud, a cuyo techo se han datado 2 muestras de la misma colada (Tabla 1), obteniéndose edades incompatibles entre sí de $\sim 1,1 \mathrm{Ma}$ y $835 \mathrm{ka}$. Esta última edad de $835 \mathrm{ka}$ es coincidente con las disponibles en la bibliografía (830$840 \mathrm{ka}$ ), de un depósito de la parte alta del escarpe sur y del relleno temprano del valle en la misma zona (ver Tabla 3a en Ferrer et al., 2020-este volumen).

Con respecto a los escarpes laterales del deslizamiento, cabe resaltar la asimetría entre ellos, apareciendo mucho más marcado el escarpe sur. En cabe- cera, los escarpes marcan dos lóbulos principales, que parecen corresponder a cabeceras de procesos diferenciados (Figuras 2 y 4 ).

$\mathrm{Si}$ bien las dataciones disponibles no permiten confirmar la ocurrencia de más de un deslizamiento en el valle, los rasgos de los escarpes y la presencia de dos paquetes potentes y separados de 'mortalón' en la galería El Drago indician esta posibilidad. En el Apartado de discusión se desarrolla con más detalle este planteamiento.

En el valle de Güímar, la ocurrencia de varios deslizamientos se vería también apoyada por las características que presentan los depósitos pleistocenos de tsunami que se conservan en Agaete (al NW de Gran Canaria), que han sido asociados a deslizamientos del flanco de Güímar, como se explica más arriba en el Apartado sobre las evidencias geológicas.

\section{Valle de Icod}

En el caso del deslizamiento de Icod, no existen rasgos morfológicos subaéreos que denoten la posible ocurrencia de más de un proceso de inestabilidad. Sin embargo, las investigaciones geofísicas submarinas de los depósitos proximales del deslizamiento (Ablay and Hurlimann, 2000; Watts and Masson, 2001), reflejan la presencia de 2 o 3 grandes lóbulos superpuestos que corresponderían a diferentes deslizamientos.

La teoría de los 'deslizamientos multietapa retrogresivos', propuesta por algunos autores en base al estudio de las características de las turbiditas procedentes del deslizamiento de Icod que ocupan las cuencas del Sistema Turbidítico Marroquí, no se considera aquí como argumento, en cuanto que no se refiere a la ocurrencia de varios deslizamientos espaciados en el tiempo, sino a la propuesta de un mecanismo de rotura para un único deslizamiento (multistage failure mechanism).

No obstante, dadas las conclusiones e implicaciones de esta teoría, con las que los autores del presente artículo no están de acuerdo, se ha considerado de interés incluir un breve resumen y discusión en el siguiente apartado. Hunt et al. (2011 y 2013b) aportan los principales argumentos sobre esta cuestión.

\section{Discusión}

Deslizamientos superpuestos en el valle de La Orotava: evidencias y edades

Las evidencias geológicas en superficie y en el interior de las galerías permiten proponer la ocurrencia de tres grandes deslizamientos superpuestos en el valle 


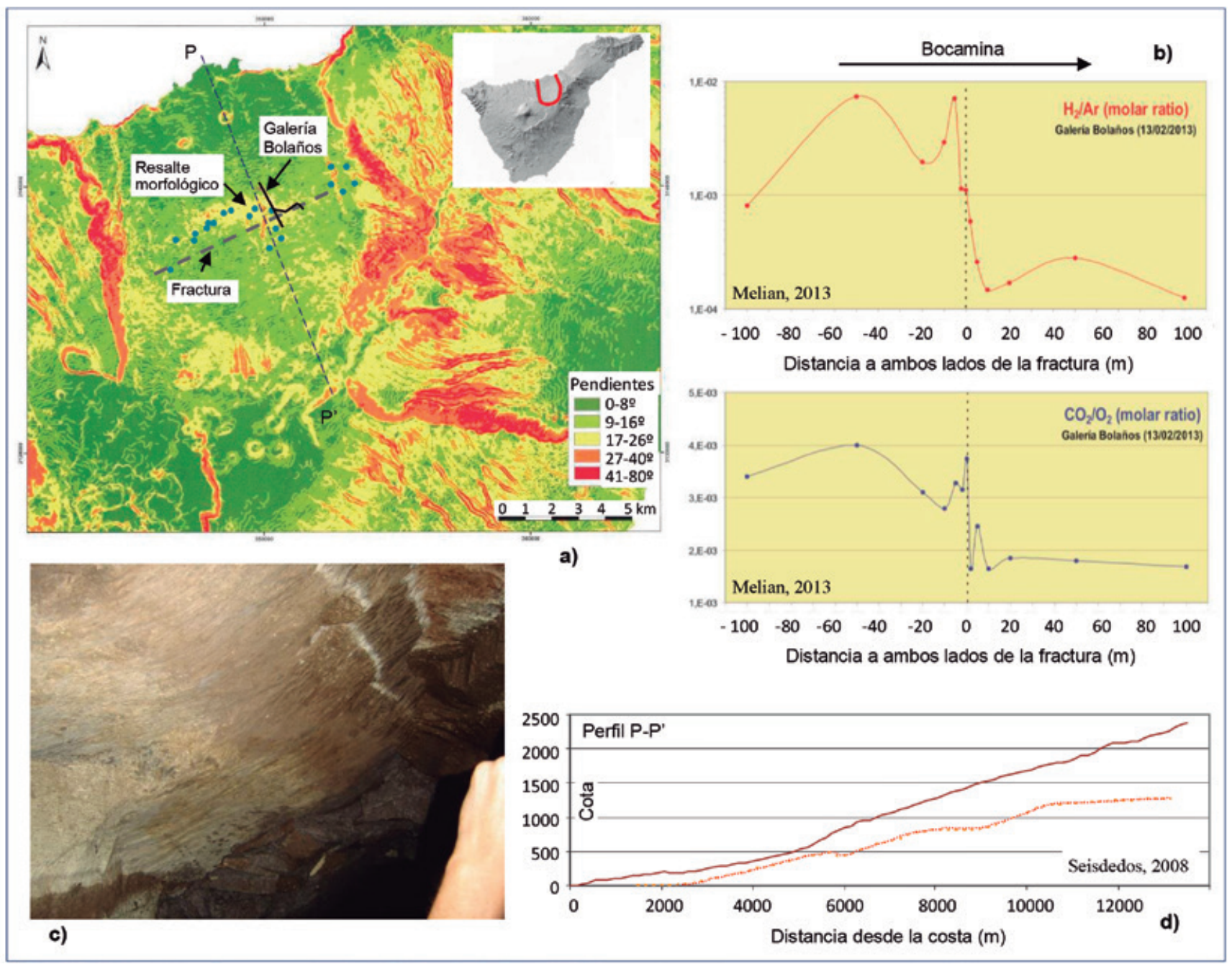

Figura 6. a) Mapa de pendientes del valle de La Orotava con la situación de la falla/fractura y la galería Bolaños que la corta en profundidad. La dirección de la fractura se ha marcado por medidas en el interior de la galería. El escalón morfológico que se observa en el mapa es coincidente con la dirección de la fractura. En superficie a lo largo de la zona de la traza de la falla existen numerosas surgencias de agua superficiales en las galerías, señaladas en el esquema con puntos azules. b) Resultados de la campaña geoquímica de medida de gases llevada a cabo en el interior de la galería Bolaños; las relaciones molares $\mathrm{H}_{2} / \mathrm{Ar}$ y $\mathrm{CO}_{2} / \mathrm{O}_{2}$ evidencian un cambio significativo que muestra un incremento de gases de origen profundo a favor de dicha fractura. c) Plano de falla en el interior de la galería Bolaños (como escala aparece una mano abajo-izda.) d) Perfil esquemático P-P' reflejando el techo de los depósitos enterrados de 'mortalón' en el valle de La Orotava, donde se observa la diferencia de espesores de los materiales de relleno sobre el 'mortalón' hacia arriba y hacia abajo del escalón morfológico, hacia la cota 500 .

Figure 6. a) Slope map of the La Orotava valley with the location of the fault/fracture and the Bolaños gallery that cuts it in depth. The direction of the fracture has been marked from measurements inside the gallery. The morphological step shown on the map coincides with the fracture strike. On the surface, along the zone of the fault line, there is substantial surface water upwelling in the galleries (blue dots). b) Results of the geochemical gas measurement campaign carried out inside the Bolaños gallery; the $\mathrm{H}_{2} / \mathrm{Ar}$ and $\mathrm{CO} / \mathrm{O}_{2}$ molar ratios show a significant change that shows an increase in gases of deep origin along the fracture. $c$ ) Fault plane inside the Bolaños gallery (as a scale appears a hand, lower-left): d) Schematic section $P$ - $P$ ' showing the roof of the buried deposits of 'mortalón' in the La Orotava valley; the difference in thickness of the filling in material on the 'mortalón' above and below the morphological step, towards level 500, is observed.

de La Orotava, confirmando las conclusiones obtenidas a partir de las nuevas dataciones realizadas por los autores (Ferrer et al., 2020-este volumen).

El primero habría sido el de mayor magnitud, afectando al flanco submarino y a la cumbre del edificio, y habría configurado los grandes escarpes laterales del valle de La Orotava, no teniendo reflejo actual en superficie sus escarpes de cabecera; otro posterior se habría desarrollado superpuesto, de menor magnitud, y sus escarpes de cabecera se reflejarían en la actual cabecera del valle; y un tercero, de menor magnitud que los anteriores, con cabecera a media ladera, coincidiendo con el escalón morfológico que se refleja en el valle de La Orotava. En el mapa de la Figura 4 y en la fotografía aérea de la Figura 7 se han representado los límites propuestos de los deslizamientos. Los dos 
últimos deslizamientos habrían ocurrido tras rellenarse de coladas los valles dejados por los anteriores. Es de suponer que estos deslizamientos, posteriores al primero y principal, arrastrarían gran parte de los depósitos de 'mortalón' dejados por los deslizamientos previos, que probablemente actuaron de planos de despegue de los posteriores.

Las principales evidencias geológicas que sustentan la propuesta de varios deslizamientos diferenciados en el tiempo, reforzada por los resultados de las dataciones, son: i) rasgos morfológicos de diferentes escarpes en superficie; ii) la presencia de planos de fractura importantes (paleo-escarpes) en el interior de la galería Bolaños y en el interior de la galería Pino Soler; estas zonas corresponderían a los escarpes de cabecera de dos de los deslizamientos; iii) la presencia de depósitos diferenciados de 'mortalón' en el interior de galerías de la zona de cabecera del valle; y iv) la presencia en la pared de la Caldera de Las Cañadas de los materiales de relleno del valle creado por el primer gran deslizamiento de La Orotava, que afloran en el Ilamado escarpe de Diego Hernández (Bravo Bethencourt y Bravo, 1989) (Figuras 2 y 6).

Los materiales de la base del escarpe de Diego Hernández se han datado en 540 ka (Ancochea et al., 1990), indicando una edad mayor para el primer y principal deslizamiento, que habría creado los grandes escarpes laterales que configuran actualmente el valle de La Orotava, con toda seguridad el escarpe occidental, y cuya cabecera alcanzaría a la zona occidental de la actual caldera de Las Cañadas; de las dataciones realizadas en rocas de los escarpes puede deducirse una edad en torno a los 560 ka (Ferrer et al., 2020-este volumen). El escarpe actual que configura la cabecera del valle de la Orotava correspondería a un deslizamiento posterior, ocurrido hace unos 510$530 \mathrm{ka}$, como reflejan las edades de las rocas datadas en las galerías (Cruz de Luis y Pino Soler, ver Figura 4) que penetran en esa zona (Ferrer et al., 2020-este volumen). Finalmente, un tercer deslizamiento habría afectado a la parte baja del valle, con escarpe de cabecera en la zona del escalón morfológico que aparece hacia la cota 500 , tentativamente datado hacia los 500 ka.

Las edades obtenidas para los dos depósitos de 'mortalón' de la galería Cruz de Luis, entre los 500 y los 530 ka si se consideran las incertidumbres (Ferrer et al., 2020-este volumen), podrían corresponder a dos deslizamientos, como se ha indicado más arriba. Un argumento para apoyar esta propuesta puede ser el lóbulo que se dibuja en la zona suroeste de la cabecera actual del valle, y que podría reflejar la cabecera de un deslizamiento local, de mucha menor magnitud que los otros descritos, claramente posterior al escar- pe principal, que habría depositado el 'mortalón' más superficial de la galería.

En la galería Cruz de Luis se ha alcanzado y datado en 2,55 Ma el sustrato de los deslizamientos bajo el depósito de 'mortalón' más profundo (Ferrer et al., 2020-este volumen). La diferencia con las edades obtenidas para las coladas sobrepuestas, de unos $2 \mathrm{Ma}$, indica que todos los materiales depositados tras el primer gran deslizamiento fueron arrastrados por el segundo, incluyendo los depósitos de 'mortalón' en el caso, poco probable, de que hubieran quedado restos importantes en estas zonas altas de cabecera. Es lógico suponer que los sucesivos deslizamientos han aprovechado los depósitos de mortalón dejados por los anteriores como planos de despegue basales.

Ante el escenario de varios deslizamientos superpuestos, cabe hacer una reinterpretación de la edad de $\sim 560$ ka que se deduce para el deslizamiento de La Orotava a partir de las dataciones subaéreas -principalmente de los escarpes- disponibles en la bibliografía (verTabla 2):

a) La edad de $560 \mathrm{ka}$, al igual que otras propuestas por diferentes autores, se ha asignado considerando un único deslizamiento de flanco, y no concuerda con las nuevas dataciones presentadas en este trabajo, procedentes de galerías, y que sí están en consonancia con las edades de depósitos submarinos, de $\sim 530$ ka (Tabla 2). Es más, de considerar una sola edad sería más representativa la de $\sim 530 \mathrm{ka}$, ya que todas las edades de la bibliografía revisada que limitan el deslizamiento por arriba (ver Tabla 2a en Ferrer et al., 2020-este volumen) no estarían en contradicción con la edad de $530 \mathrm{ka}$, y de las que lo limitan por abajo únicamente una edad no encajaría (la edad de $566 \pm$ 13 ka de unas lavas en "cascada" sobre el escarpe de Santa Úrsula; Carracedo et al., 2009), ya que las dos edades de Ancochea et al. (1990; $560 \pm 30$ ka y $540 \pm$ $60 \mathrm{ka}$, esta última de la pared de Diego Hernández), quedarían ajustadas al considerar sus incertidumbres.

b) $\mathrm{Si}$, por contra, se considera la ocurrencia de tres grandes deslizamentos, como aqui se postula, se puede sustentar la hipótesis de un primer deslizamento en torno a los $560 \mathrm{ka}$, conformando ya los grandes escarpes laterales de rotura, como reflejan la mayoría de dataciones de rocas de los escarpes del valle (verTabla 2a en Ferrer et al., 2020-este volumen). Otro posterior entorno a los $530 \mathrm{ka}$, reflejado en los depósitos de 'mortalón' de las galerias datadas y en los depósitos turbidíticos de la Llanura Abisal de Madeira (MAP) (Hunt et al., 2013a), además de otras evidencias morfológicas arriba explicadas; todas las dataciones realizadas en rocas de galerias del valle de La Orotava han proporcionado edades en torno a los 510-530 ka para las rocas a techo de los depósitos de 'mortalón'; 


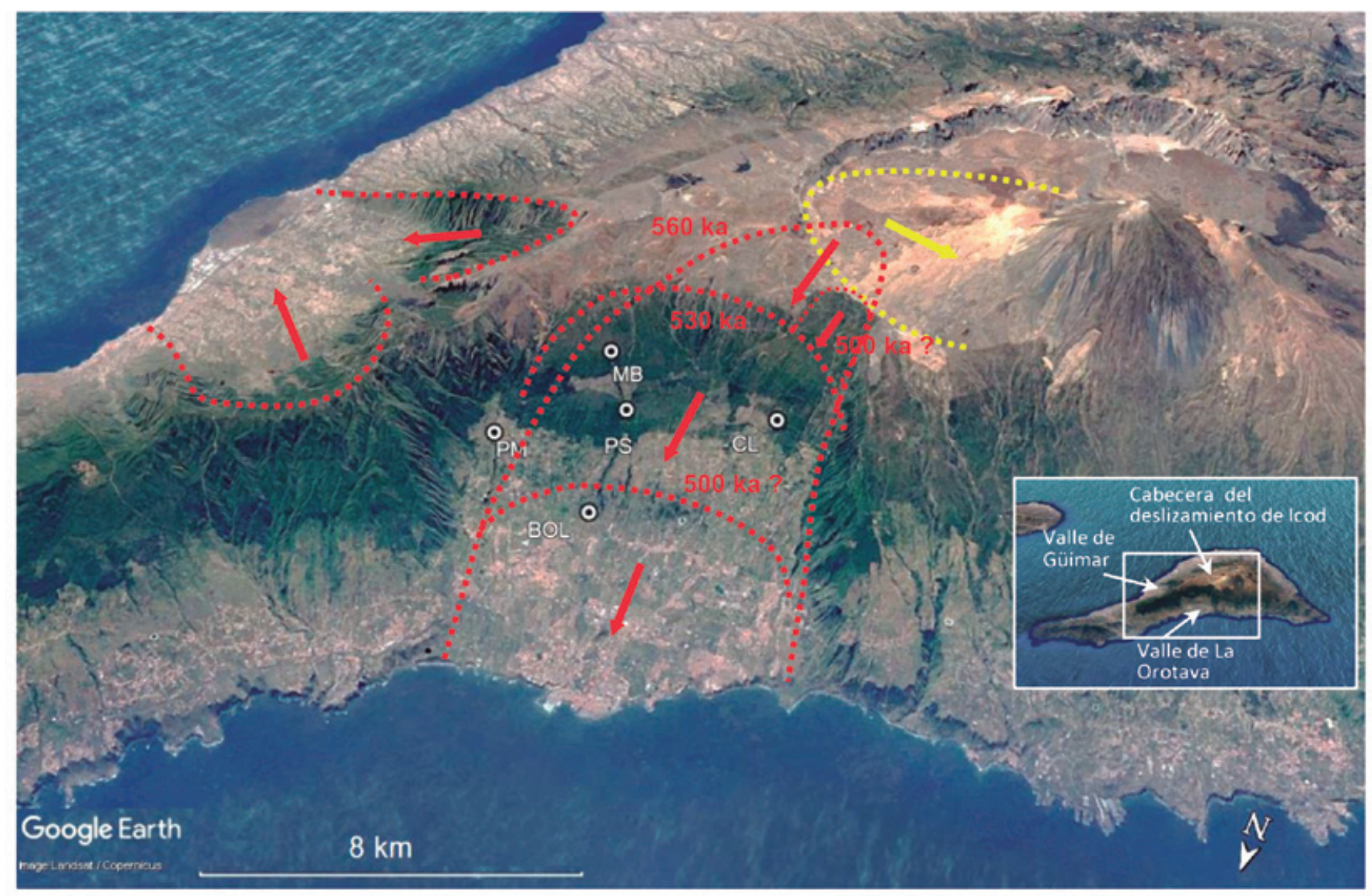

Figura 7. Vista aérea desde el norte de los valles de La Orotava y Güímary de la Caldera de Las Cañadas rodeando al PicoTeide. Se han representado los límites propuestos para los deslizamientos superpuestos de La Orotava, y sus posibles edades, y los deslizamientos solapados del valle de Güímar (línea discontinua roja). Se ha marcado igualmente la cabecera del deslizamiento de Icod (línea amarilla). Sobre el valle de La Orotava se indica la situación de la bocamina de las galerías Bolaños (BO), Cruz de Luis (CL), Pino Soler (PS), Montaña Blanca (MB) y Pasada de Montelongo (PM). Ver el mapa de la Figura 4. Mapa base: Google Earth.

Figure 7. Aerial view from the north of the valleys of La Orotava and Güímar, and of the Caldera de Las Cañadas surrounding Pico Teide. The proposed limits for the overlapping landslides of La Orotava and Güímar valley have been represented (red dashed line). The head of the Icod landslide has also been marked (yellow line). In the La Orotava valley, the location of the entrance to the galleries is indicated: Bolaños (BO), Cruz de Luis (CL), Pino Soler (PS), Montaña Blanca (MB) y Pasada de Montelongo (PM). See Figure 4. Base map: Google.

el escarpe de rotura de este deslizamento conforma la cabecera actual del valle, y podría estar reflejado en profundidad en los últimos tramos de la galería Pino Soler. Algunas de las dataciones realizadas por los autores y otras de la bibliografía (p.e. en turbiditas de la MAP; Weaver et al., 1992; ver Ferrer et al., 2020-este volumen) permiten plantear un tercer deslizamiento hacia los $\sim 500 \mathrm{ka}$, cuyo escarpe de cabecera estaría marcado por el escalón morfológico que aparece en medio del valle, que refleja en superficie la fractura atravesada por la galería Bolaños.

La segunda propuesta se ve reforzada por las evidencias geológicas y morfológicas que se han descrito anteriormente, y por las nuevas dataciones Ar/Ar, y concuerdan con las dataciones disponibles de los depósitos de turbiditas provenientes de los materiales deslizados del valle de La Orotava (Tabla 2).

De las nuevas dataciones (Tabla 1), puede deducirse que el sustrato de los deslizamientos solo está representado por los materiales muy antiguos de $>2,5$ Ma alcanzados en la galería Cruz de Luis; las otras dataciones realizadas a muro de depósitos de 'mortalón', en galerías de La Orotava, con edades en torno a los 500-530 ka, representarían depósitos de relleno de valle tras un deslizamiento (o deslizamientos) posterior al principal y más profundo.

\section{Deslizamientos en el valle de Güímar}

Entre las evidencias que apuntarían a la ocurrencia de más de un deslizamiento en el valle de Güímar se encuentra la presencia de dos extensos tramos de 'mortalón' en la galería El Drago. Al más profundo y antiguo, podría asignarse de forma tentativa una edad $\geq 1 \mathrm{Ma}$, según una datación propia realizada a techo del depósito (Tabla 1); el otro depósito de 'mortalón', más cercano a bocamina, correspondería a un deslizamiento posterior, al que bien pudiera asignarse la 
edad de unos 830-840 ka, estimada por las dataciones bibliográficas y en consonancia con los resultados de otra datación propia (Ferrer et al., 2020-este volumen). En este caso se trataría de deslizamientos muy alejados en el tiempo ( $\geq 160 \mathrm{ka})$. Así, siguiendo esta hipótesis, el tramo de 'mortalón' que aparece en la cercana galería Cueva de Las Colmenas (Figura 4) correspondería al deslizamiento más antiguo, ya que la datación de la colada sobre él aporta una edad similar, en torno a 1,1 Ma (DAT-1, Tabla 1). Pero esto queda desestimado si se da por buena la datación posterior realizada sobre la misma colada (muestra CCO-2215, Tabla 1) de la galería Cueva de Las Colmenas, para la que resultó una edad de $835 \mathrm{ka}$. No hay justificación para esta diferencia de más de 250 ka en la misma colada, a pesar de haberse considerado a priori válidas las dos dataciones, y por tanto una de las dos tiene que ser errónea.

Dicho de otro modo, los resultados de dos dataciones en muestras de las galerías Cueva de Las Colmenas y El Drago, dan una edad prácticamente similar en torno a 1,0-1,1 Ma (Tabla 1), lo que no es compatible con la edad asignada al deslizamiento de Güímar, 830$840 \mathrm{ka}$, por datos de la bibliografía y otro resultado de las dataciones propias (Tabla 1).

La explicación de que los depósitos de 'mortalón' bajo las coladas datadas en torno a 1 Ma pudieran corresponder a un deslizamiento más antiguo, no puede sustentarse al haberse obtenido edades contradictorias para la misma colada en la galería Cueva de Las Colmenas. No obstante, es de consideración el hecho de que se haya obtenido la misma edad, en torno a 1,0-1,1 Ma, para el techo del 'mortalón' en las muestras de las dos galerías cercanas, coincidiendo con el rango que delimita la edad de la última fase de desarrollo de la dorsal NE, entre los 0,8 Ma y $1 \mathrm{Ma}$ (Carracedo et al., 2009).

Por otro lado, en el valle de Güímar evidencias geológicas subaéreas y subterráneas apuntan a la ocurrencia de al menos dos grandes deslizamientos; a partir de los rasgos morfológicos de los escarpes la hipótesis más probable sería la de dos deslizamientos de magnitud parecida, paralelos entre sí y con sus cabeceras secantes (ver Figuras 4 y 6 ). Este supuesto se ve avalado por las notables diferencias morfológicas entre los dos escarpes laterales que limitan al norte y al sur el actual valle de Güímar, y por la configuración lobulada del escarpe de cabecera, hacia cuyo centro aparece un resalte irregular en el que una galería excavada de $3.500 \mathrm{~m}$ de longitud (Barranco de Amance, ver Figura 4) no atraviesa depósitos de 'mortalón', estando muy próxima a las galerías de El Drago y EI Aderno que sí atraviesan tramos importantes del mismo, todas ellas visitadas por los autores. Las galerías
El Drago y Barranco de Amance se caracterizan por presentar una elevada intensidad de fracturas, fallas, diques y zonas alteradas en sus zonas profundas, asociadas al escarpe de cabecera del deslizamiento.

Por último, los depósitos de tsunami que aparecen al NW de Gran Canaria, atribuidos al deslizamiento de Güímar (Pérez-Torrado et al., 2006; Giachetti et al., 2011), presentan características estratigráficas y sedimentológicas que reflejan tres depósitos correspondientes a diferentes tsunamis (Andrade et al., 2010; Madeira et al., 2011a), sin poder precisar edades ni intervalos de tiempo entre ellos.

\section{Sobre la hipótesis de los 'múltiples deslizamientos retrogresivos' en el flanco de lcod}

Wynn and Masson (2003) y Masson et al. (2006) proponen, tras el estudio de turbiditas en la Cuenca de Agadir provenientes de los deslizamientos más recientes de las islas Canarias (Icod y El Golfo, este último en la isla de El Hierro) que el deslizamiento fuente de las turbiditas, formadas por apilamiento de varias subunidades, probablemente ocurrió en varias etapas ("several retrogressive stages") con períodos de separación de horas o días, en lugar de una rotura masiva e instantánea de flanco ("... a sequence of flows emplaced over a period of hours to days"). En el caso de la turbidita g de Icod, Wynn and Masson (2003) diferencian 9 subunidades apiladas, que corresponderían a 9 episodios o fases de rotura dentro de un único gran deslizamiento. Bajo esta interpretación, los autores describen un escenario donde, tras la principal rotura inicial, que dejaría grandes escarpes inestables en el flanco de la isla, ocurrieron otras varias roturas sucesivas, generando cada una de ellas corrientes de turbidez.

En estudios más detallados, Hunt et al. (2011) diferencian por su composición y características físicas 2 paquetes en la turbidita g de la Cuenca de Agadir y la Llanura Abisal de Madeira, procedente del deslizamiento de Icod, y la dividen en 7 subunidades, con 3 subunidades el paquete basal y 4 el superior, cuya principal diferencia es que las basales, más potentes, presentan componentes minerales de los flancos submarinos de la isla de Tenerife, y las superiores únicamente componentes de materiales subaéreos. Los citados autores deducen que las 7 subunidades que identifican en la turbidita representan 7 etapas de rotura separadas varios días entre sí ("... at least several days between each stage of failure").

Es decir, Hunt et al. (2011), siguiendo la teoría de Wynn and Masson (2003), proponen que las roturas de flanco volcánico ocurren en múltiples etapas sucesivas ("multistage failures at a single source") con 
días de separación entre ellas, y descartan otras posibles causas para el origen de las multicapas diferenciadas en las turbiditas por su composición mineralógica, como reflexiones de flujo, confluencia de flujos de diferentes canales, o varios deslizamientos simultáneos procedentes de distintas zonas. Estas causas son igualmente desestimadas por Wynn and Masson (2003) en su estudio sobre las turbiditas b y g de la Cuenca de Agadir, procedentes de los deslizamientos de El Golfo e Icod, respectivamente. Sin embargo, Hunt et al. (2011) no explican cómo se forman las multicapas de turbidita, y afirman desconocer el mecanismo para la generación de corrientes de turbidez de cada etapa del deslizamiento.

A este respecto cabe resaltar la complejidad en lo referente al origen de los depósitos de turbiditas de la Llanura Abisal de Madeira (MAP), donde las procedentes de la Cuenca de Agadir y de los deslizamientos del norte de Tenerife convergen con megadebris flow procedentes de los deslizamientos de las islas de El Hierro y La Palma, el denominado Canary Debris Flow, implicando que los mecanismos y factores que controlan el transporte de sedimentos desde los flancos deslizados de las islas hasta las llanuras abisales sean controvertidos (León et al., 2019).

No se discute aquí la validez de la propuesta de Hunt et al. (2011) para el mecanismo de rotura, porque se considera inverosímil. La existencia de varias capas de turbiditas no justifica un deslizamiento para cada una de ellas. ¿Cómo explicar este escenario de varias grandes roturas, siete o más, en masas rocosas como son los edificios volcánicos, cada pocas horas o días, combinadas con una gran erupción explosiva entre ellas, como proponen los citados autores?; ¿o cómo se estiman estos cortos lapsos de tiempo uniformes entre uno y otro derrumbe?; ¿o cómo explicar la llegada de sucesivas corrientes de turbidez en horas o días y el depósito ordenado de las mismas?; ¿o por qué se atribuye cada una de las capas de turbiditas a un deslizamiento distinto y no, al menos las más superiores, a productos de erupciones explosivas?.

La conclusión de un megadeslizamiento que se produce en 7 etapas "retrogresivas", una cada pocos días, resulta incompatible con los mecanismos de inestabilidad y rotura de los grandes flancos volcánicos (Schiffman et al., 2006; Ferrer et al., 2010 y 2015; Seisdedos et al., 2012), y con la profundidad de las superficies de deslizamiento que indican las observaciones en las galerías que atraviesan los rellenos del valle del deslizamiento de Icod.

Cabe por tanto plantearse otras explicaciones posibles sobre los procesos que pueden dar lugar a un apilamiento de múltiples capas de turbiditas a cientos de kilómetros, hasta 1.000 kilómetros, de la fuente del deslizamiento, como un desfase temporal en la llegada de los materiales en suspensión a las cuencas de depósito, o que se produjera en oleadas provocadas por los reajustes gravitacionales de las enormes masas rocosas rotas y caídas al mar de forma violenta, etc.

Sí son de interés sin duda los datos de Hunt et al. (2011) referentes a la presencia de minerales submarinos y/o subaéreos en las diferentes capas, así como la presencia de materiales de la unidad El Abrigo en la parte alta del depósito (ver Ferrer et al., 2020-este volumen para explicaciones). Lo primero podría indicar la llegada en primer lugar de corrientes de turbidez con restos de los materiales rotos y deslizados en el flanco submarino, e inmediatamente después las partículas procedentes del deslizamiento subaéreo; lo segundo representaría los productos de la explosión final desencadenada por el deslizamiento.

En cualquier caso, como se ha indicado más arriba, la hipótesis de los múltiples deslizamientos retrogresivos cada pocos días, que conformarían en conjunto un único y gran deslizamiento de flanco, no tiene cabida en la propuesta de grandes deslizamientos superpuestos en un mismo flanco volcánico, alejados en el tiempo al menos unos cuantos miles de años, como aquí se propone.

\section{El deslizamiento de la isla de Ritter: el más reciente y de mayor magnitud ocurrido en época histórica}

En relación con los procesos de apilamiento de capas de turbiditas provenientes de deslizamientos de flanco de islas volcánicas, Watt et al. (2019) estudian los depósitos submarinos del deslizamiento de la isla de Ritter, en Papua Nueva Guinea, ocurrido en 1888, concluyendo que una única rotura catastrófica puede dar lugar a depósitos complejos de multi-turbiditas, en contra de la propuesta de múltiples deslizamientos para generar cada una de las capas de turbidita. La cercanía en el tiempo de este deslizamiento, y las observaciones directas de sus efectos en su día, permiten deducir la forma en que se desarrolló el proceso submarino.

El deslizamiento de flanco de la isla de Ritter es el de mayor magnitud $\left(>2 \mathrm{~km}^{3}\right)$ y más reciente ocurrido en una isla volcánica, y junto con el de la isla de Oshima-Oshima, en el mar del Japón, en 1741, con un volumen parecido (Satake, 2007), son los dos únicos deslizamientos de flanco de isla volcánica de $>1 \mathrm{~km}^{3}$ ocurridos en época histórica. Aunque de magnitud mucho menor que los deslizamientos prehistóricos de Tenerife, y en contextos geológicos diferentes, en los dos casos históricos los procesos consistieron en roturas de flanco que destruyeron una gran parte de 
la isla, incluyendo su cumbre, que causaron enormes tsunamis al entrar violentamente en el mar las avalanchas rocosas, y que estuvieron asociados a erupciones (en el caso de Ritter, el deslizamiento desencadenó una erupción submarina en el flanco deslizado, por descompresión de la cámara magmática; en el caso de Oshima-Oshima el deslizamiento se asocia a una gran erupción), todos ellos procesos comparables, salvando las escalas, a los ocurridos en el deslizamiento de Icod.

Para el caso de Ritter, la rotura afectó al edificio subaéreo y, mayoritariamente, al submarino, estimándose un volumen de $\sim 2,4 \mathrm{~km}^{3}$ (Karstens et al., 2019); de hecho, la isla desapareció bajo el mar excepto una parte del escarpe de cabecera de unos $9 \mathrm{~km}$ de longitud. Las masas rocosas deslizadas al mar se extendieron decenas de $\mathrm{km}$ hacia el noroeste de la isla, depositándose facies distales de turbiditas a partir de los 75-80 km, más allá de los depósitos lobulados característicos de las avalanchas de derrubios submarinas. La interpretación de los resultados de los estudios geofísicos y del análisis de las muestras obtenidas de los depósitos turbidíticos, llevan a Watt et al. (2019) a interpretar que se trata de un depósito distal estratigráficamente complejo de capas o sub-unidades de turbiditas provenientes de un único deslizamiento catastrófico, hecho constatado porque el rápido deslizamiento generó un único tren de olas de tsunami, según los testimonios de la época.

Sobre la formación de la turbidita multi-capa de Ritter, Watt et al. (2019) concluyen que las múltiples subunidades diferenciadas no necesariamente tienen que estar separadas por intervalos de tiempo (con la posible excepción de la corriente de turbidez generada por la erupción posterior al colapso, que formó la unidad superior de la turbidita), sino que pueden explicarse por una combinación de flujos de evolución compleja por las vías de transporte seguidas y la topografía del fondo marino (reflexiones de corriente), por la erosión y arrastre e incorporación de los sedimentos del fondo marino a los flujos, y por la erupción magmática provocada por el colapso inicial.

Estas conclusiones apoyan las ideas de los autores de este trabajo sobre la poca verosimilitud de las hipótesis de múltiples deslizamientos retrogresivos propuestas para el deslizamiento de Icod.

\section{Relación temporal entre el deslizamiento de Icod y el blast de El Abrigo}

La relación entre la gran erupción explosiva del final del ciclo Cañadas y el último deslizamiento del edificio Cañadas III, que formó definitivamente la caldera ac- tual, ha sido postulada por la mayoría de los investigadores en las últimas décadas (ver el apartado sobre las dataciones del deslizamiento de Icod en Ferrer et al., 2020-este volumen), considerándose ambos hechos prácticamente coetáneos (Ancochea et al., 1999; Hunt et al., 2013a). Sobre la relación causal entre ambos, algunos autores deducen que el segundo pudo ser posterior o la consecuencia del primero (Ancochea et al., 1999; Edgar et al., 2007; Hunt et al., 2011; Martí, 2019), mientras que otros consideran que la erupción explosiva fue una consecuencia inmediata del deslizamiento del flanco norte del edificio volcánico (Huertas et al., 2002; Carracedo et al., 2007; Boluesteix et al., 2012; Coello et al., 2014), por despresurización repentina de la cámara magmática. A este respecto, aunque sin mencionar explícitamente el deslizamiento de Icod como origen de la parte oriental de la caldera (la zona de la pared de Diego Hernández, Figura 2), Bravo Bethencourt y Bravo (1989) indican la ausencia de depósitos de proyección explosiva con sienitas sobre los materiales posteriores al "gran fenómeno de la desaparición de la cúpula central" del escudo de Las Cañadas, estableciendo así una relación cronológica entre el "gran fenómeno" (el deslizamiento de Icod) y el depósito explosivo.

Algunos autores han propuesto una gran explosión lateral tipo blast, desencadenada por el deslizamiento (Ancochea et al., 1999; Schmincke et al., 1999), que habría originado los característicos depósitos piroclásticos con abundantes fragmentos líticos y de sienitas, de hasta 8-10 m de potencia, típicos de flujos piroclásticos, que aparecen en retazos en el norte y centro de la isla, en la zona oriental de la cumbre del Edificio Cañadas, coronando la pared de la caldera; en la costa norte, los depósitos del blast aparecen al oeste, en la zona de Isla Baja, formando niveles masivos muy ricos en líticos de hasta $3 \mathrm{~m}$ de potencia, y sobre el valle de La Orotava.

Autores como Ancochea et al. (1999) y Pittari et al. (2006 y 2008), entre otros, correlacionan estos depósitos explosivos con los depósitos ignimbríticos de El Abrigo, de igual edad, extendidos sobre el flanco SE y la zona de la caldera, asociando todos ellos a la gran erupción explosiva de El Abrigo y a la génesis de la caldera de Las Cañadas. Sin embargo, para otros autores esta correlación es incierta.

La relación temporal entre el deslizamiento y la erupción de El Abrigo es establecida por Hunt et al. (2011 y 2013b) a partir del estudio en detalle de la turbidita g del SistemaTurbidítico Marroquí, cuya procedencia se asigna al deslizamiento de Icod. Los autores dividen la turbidita en 7 subunidades o episodios por criterios sedimentológicos y geoquímicos, de lo que deducen que el deslizamiento tuvo lugar en diferentes 
etapas o fases de rotura, separadas entre sí unos días. Los análisis del vidrio volcánico indican que en cada subunidad de la turbidita de Icod está presente material procedente de la Formación Diego Hernández (FDH), y únicamente el episodio más reciente contiene vidrio de composición similar a los de la unidad El Abrigo, el depósito ignimbrítico que corona la FDH, constituido por una brecha con clastos de sienita (ver Apartado sobre la edad del deslizamiento de Icod; Ferrer et al., 2020-este volumen); esto es considerado por los autores citados para concluir que la erupción explosiva que dio lugar al depósito de El Abrigo habría sido posterior al grueso del deslizamiento de Icod, pero previa a un último episodio del deslizamiento, sin entrar a considerar los factores causantes y desencadenantes de la erupción ni del deslizamiento de flanco.

Sin embargo, para los autores del presente trabajo es más razonable y verosímil la hipótesis de que la parte superior de la turbidita g, que contiene material de la unidad El Abrigo según Hunt et al. (2011), sea el resultado de los productos del blast-de los flujos piroclásticos al entrar violentamente en el mar y de los fragmentos proyectados- mezclados con los materiales procedentes de las avalanchas de derrubios del gran deslizamiento de flanco ocurrido, probablemente, inmediatamente antes, en contraposición a la hipótesis de que los acontecimientos (deslizamientos y explosión) ocurrieran de forma sucesiva y ordenada en el tiempo, como indican Hunt et al. (2011).

NOTA: Resulta difícil comprender qué mecanismos gobiernan la deposición de capas turbidíticas de tal forma que entre una y otra pasen unos días, y lleguen a depositarse de forma ordenada y diferenciada, sobre todo considerando que las partículas provienen de un deslizamiento a cientos de $\mathrm{km}$, y las corrientes de turbidez deben recorrer caminos sinuosos para llegar a las zonas de deposición. Sobre las conclusiones de Hunt et al. (2011) de que las turbiditas multicapa de Icod se habrían formado por múltiples deslizamientos retrogresivos con intervalos de unos días, en el apartado anterior, al tratar sobre el deslizamiento de Icod, se discuten algunos aspectos de interés.

Aquí se presenta una nueva evidencia del orden en que sucedieron ambos acontecimientos. La investigación de los depósitos de megatsunamis causados por el deslizamiento de Icod, recientemente descubiertos en la zona de Teno y Buenavista, al norte de Tenerife (Madeira et al., 2011b; Ferrer et al., 2013; Coello et al., 2014; Paris et al., 2017), ha permitido establecer la relación temporal entre el blasty el deslizamiento. Estos depósitos caóticos, de hasta 3,5 $\mathrm{m}$ de potencia en algunas zonas, presentan dos niveles claramente diferenciables separados por una superficie ondulada, en ocasiones erosiva. El nivel basal está compuesto exclusivamen- te por bloques y clastos angulares y heterométricos de basalto, con fábrica caótica y escasa matriz arenosa, conteniendo fósiles terrestres y marinos (Figura 8); hacia techo aparecen los bloques de mayor tamaño, de hasta 1 metro, sugiriendo una gradación inversa. En contraste, el nivel superior es una brecha con fragmentos heterométricos de basalto, sienita, fonolita, clastos anaranjados con alteración hidrotermal y pumitas, con granulometría mucho más fina que el nivel basal y tamaños dominantes de 1 a $5 \mathrm{~cm}$, y contenido fósil marino y terrestre menos abundante. La composición litológica del nivel superior es similar a la de los depósitos del blast que aparecen repartidos por las zonas norte y central de la isla de Tenerife, con espesores de hasta varios metros (Figura 8), lo que indica un mismo origen y procedencia de los materiales.

Estas características de los depósitos evidencian que el megatsunami debió estar provocado por un gran deslizamiento de flanco seguido de una explosión volcánica (blast), ambos eventos separados por un intervalo de tiempo muy corto. En primer lugar, penetraron violentamente en el mar las avalanchas rocosas procedentes del gran deslizamiento, causando la primera o primeras olas gigantes, $y$, posteriormente, llegaron al mar los productos de la gigantesca explosión, que alcanzarían violentamente el mar en forma de nubes ardientes provocando nuevas y enormes olas; posiblemente estos productos se mezclaron con las últimas avalanchas de las rocas deslizadas. EI intervalo de tiempo entre ambos procesos violentos y repentinos pudo haber sido muy corto, de solo unos pocos minutos o segundos, como corrobora el hecho de que la superficie ondulada erosiva que separa los dos niveles diferenciados en los depósitos de tsunami no presenta ninguna evidencia de un intervalo de tiempo entre ambos.

Esta consideración apoya la tesis de que los grandes deslizamientos de flanco de volcanes oceánicos no son desencadenados por erupciones explosivas en los edificios volcánicos, ni tienen por qué ir asociados necesariamente, aunque puede darse el caso, como en el deslizamiento de Icod. Como apuntan Boulesteix et al. (2012), entre otros autores citados por ellos, los deslizamientos gigantes de islas oceánicas pueden controlar el desarrollo de los procesos eruptivos; la desaparición instantánea de volúmenes importantes de un edificio volcánico afecta inmediatamente al campo tensional local, y puede provocar cambios bruscos en los sistemas magmáticos y desencadenar explosiones laterales destructivas.

La rotura de un flanco de un edifico de varios miles de metros de altura a favor de planos de deslizamiento submarinos, no puede explicarse ni justificarse sino por la pérdida de resistencia en las zonas basales sub- 
marinas, debido a factores relacionados con la enorme altura y peso de los edificios, las pendientes de sus flancos y la naturaleza y propiedades mecánicas de los materiales sobre los que se apoya el edificio subaéreo (Ferrer et al., 2010 y 2015; Seisdedos et al., 2012). Las características de los numerosos casos de deslizamientos gigantes de flancos volcánicos en las islas Canarias y en Hawaii, los más espectaculares y emblemáticos del planeta, apoyan estos mecanismos de rotura por las causas citadas, sin la influencia necesaria de otros factores condicionantes o desencadenantes, en ocasiones sin justificación ni relación alguna con el desarrollo de los procesos, a los que con frecuencia se les atribuye un papel importante o definitivo, como el cambio de condiciones climáticas y del nivel del mar (McMurtry et al., 2004; Boulesteix et al., 2013; Hunt et al., 2013a; Ablay and Hurlimann, 2000), los terremotos volcánicos, procesos magmáticos y esfuerzos tectónicos tensionales (Urgeles et al., 1997 y 2001; Martí et al., 1997; Martí, 2019), intrusión de diques (Elsworth and Day, 1999; Krastel et al., 2001), exceso de presión de poros (Urgeles et al., 2001), o la presencia de suelos arcillosos residuales (Hurlimann et al., 1999).

Hunt et al. (2014) incluyen un completo resumen del estado del arte sobre las causas de estos grandes movimientos de masas como introducción en un artículo sobre las turbiditas procedentes de Canarias, para concluir que el tema de los factores relacionados con el vulcanismo que condicionan o desencadenan los deslizamientos de flanco está sin resolver. De igual forma, Masson et al. (2006) concluyen al respecto que no se conocen las causas y factores desencadenantes de las roturas de flanco. Recientemente, Hunt et al. (2018) concluyen que los deslizamientos de Tenerife fueron inicialmente desencadenados por los propios procesos volcánicos (erupciones y sismicidad), al debilitar los flancos submarinos del edificio volcánico, propuesta sin ninguna verosimilitud basada en sus estudios de las características y composición de las turbiditas procedentes de los deslizamientos. Martí (2019), para justificar la teoría de que el deslizamiento ocurrió posteriormente a la gran explosión de El Abrigo (la cual según este autor formó la caldera de Las Cañadas) y hacerla compatible con la hipótesis de Hunt et al. (2011) de los multi-deslizamientos retrogresivos, apunta la posibilidad de que los productos del deslizamiento y de la explosión se mezclasen en el mar, lo cual es muy razonable, y probablemente ocurrió, pero esta teoría es incompatible con el hecho de que la capa basal de los depósitos del megatsunami del deslizamiento de Icod, está formada únicamente por bloques de basalto, mientras que la superior sí presenta productos de la explosión.

A este respecto, cabe indicar que el desconocimiento general de los factores que desencadenan las roturas de los edificios volcánicos tiene que ver en parte con las dificultades de abordar las investigaciones de unos procesos prehistóricos a escala geológica (deslizamientos de grandes masas rocosas con volúmenes muy por encima de los mayores procesos históricos conocidos) y el estudio de las características y propiedades mecánicas de los materiales que forman los edificios volcánicos.

Sin embargo, algunos autores, en base a los principios de la mecánica de masas rocosas y las características y comportamiento de los particulares materiales submarinos que forman la base de las islas volcánicas, las hyaloclastitas, proponen que estos materiales son el principal factor que condiciona definitivamente los megadeslizamientos de los edificios volcánicos oceánicos (Oehler et al., 2005; Schiffman et al., 2006; Ferrer et al., 2010 y 2015). En efecto, las propiedades mecánicas de las hyaloclastitas, rocas que se forman en erupciones submarinas a varios cientos de metros $(>1 \mathrm{~km})$ por debajo del nivel del mary hasta la superficie, bajo unas determinadas condiciones de presión y temperatura, controlan la estabilidad de los flancos de las islas volcánicas, caracterizados por sus elevadas pendientes. La altura, pendiente y peso que alcanzan las islas en su rápido crecimiento determinan las condiciones de equilibrio de los flancos, que pueden sobrepasar el estado límite y romper al superarse la resistencia de los materiales basales submarinos: las hyaloclastitas.

\section{Evidencias del delizamiento de Micheque}

El deslizamiento de Micheque o Acentejo, en el flanco norte de la isla, no se incluye en la mayoría de los trabajos sobre los grandes deslizamientos de flanco de Tenerife. Sin embargo, su existencia es irrefutable, a pesar de no tener ningún rasgo morfológico visible en superficie, lo que imposibilita precisar sus límites y su extensión. Algunos autores han aportado, en un sentido u otro, datos que evidencian la presencia de este deslizamiento.

Coello (1973) y Coello y Bravo (1989) presentan un corte geológico de la Cordillera Dorsal, al noreste del valle de La Orotava, con los materiales atravesados por las galerías de agua excavadas en la zona, mostrando una formación denominada 'brecha volcánica' (el 'fanglomerado' de Bravo, 1962), cubierta por potentes series de coladas y piroclastos, que aparece bajo el escarpe de Santa Úrsula y extendiéndose al noreste. Estos depósitos de 'mortalón' corresponderían al deslizamiento de Micheque, ya que quedan claramente fuera del valle de La Orotava.

Ablay and Hurlimann (2000) dedujeron la existencia de un deslizamiento en la zona norte del flanco NE 


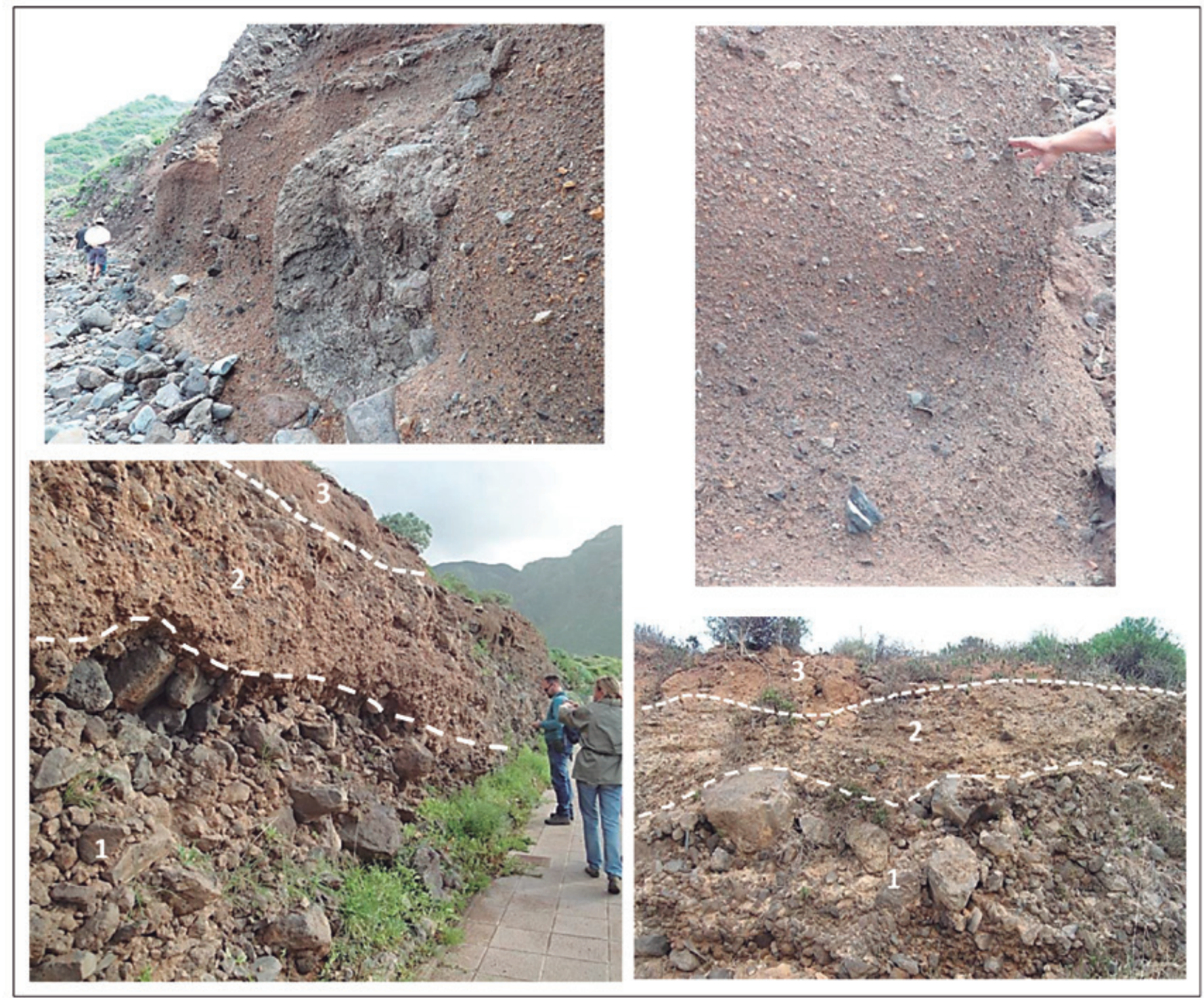

Figura 8. Arriba izda. y dcha.: Depósito del blast en la zona de Buenavista (NW de Tenerife), formado mayoritariamente por fragmentos líticos y pómez de pequeño tamaño en matriz fina, conteniendo clastos de sienitas nefelínicas. Abajo izda. y dcha.: Depósitos de tsunami en la misma zona con dos niveles claramente diferenciados, separados por una superficie ondulada, localmente erosiva, sin evidencia de un intervalo de tiempo significativo entre ellos; la capa inferior (1), está compuesta exclusivamente de bloques y cantos heterométricos de basalto, con estructura caótica y escasa matriz arenosa, tamaño centimétrico hasta métrico, con los elementos más grandes en la parte superior, mostrando una gradación inversa; la capa superior (2), de 1,5 m de espesor, contiene fragmentos y clastos de las mismas litologías que aparecen en el depósito del blast: basalto, sienita, fonolita, cantos anaranjados con alteración hidrotermal y fragmentos de pómez, con un tamaño predominante de $1-5 \mathrm{~cm}$, máximo $20 \mathrm{~cm}$; (3) depósito coluvial.

Figure 8. Above: Blast deposit in the Buenavista area (NW of Tenerife), formed mainly by small lithic fragments and pumice in a fine matrix, with clasts of nepheline syenites. Bottom: Tsunami deposits in the same area with two clearly differentiated levels, separated by a locally eroded, undulating surface, with no evidence of a significant time interval between them; the lower layer (1), is composed exclusively of heterometric blocks and fragments of basalt, $\mathrm{cm}$ to $\mathrm{m}$ size, with a chaotic structure and scarce sandy matrix, with the largest elements at the top, showing an inverse gradation; the upper layer (2), $1.5 \mathrm{~m}$ thick, contains fragments and clasts of the same lithologies that appear in the blast deposit: basalt, syenite, phonolite, orange fragments with hydrothermal alteration and pumice, with a size predominantly 1-5 $\mathrm{cm}$, maximum $20 \mathrm{~cm}$; (3) colluvial deposit.

de la dorsal (al que denominaron East Dorsal) por la morfología de los depósitos de avalancha submarinos frente a la costa noreste deTenerife, proponiendo una edad imprecisa menor que la del deslizamiento de La Orotava, por la disposición de los depósitos submarinos lobulados de ambos.
Carracedo et al. (2009), describen los materiales atravesados por dos galerías excavadas en el flanco NE de la Cordillera Dorsal, en la zona de Santa Úrsula, que alcanzan depósitos de 'mortalón' que atribuyen al deslizamiento de Micheque. Se trata de las galerías Dornajos y EI Loro; en la primera de ellas los citados 
autores datan las lavas antes y después del 'mortalón', y estiman la edad mínima del deslizamiento en unos 830 ka. Estos autores indican, con respecto al deslizamiento East Dorsal de Ablay y Hurliman (2000), que o bien la interpretación de la edad asignada es incorrecta o bien se trataría de un deslizamiento más joven del que no existe ninguna prueba o evidencia. Cabe indicar que, según la información disponible del CIATF (2019) sobre los datos de las galerías, Carracedo et al. (2009) confunden la situación y los trazados de las galerías Dornajos y EI Loro con otras dos galerías cercanas, las de María García y Salto Morisco, como se refleja en los mapas de su publicación, y aportan un dato erróneo para la longitud de la galería Dornajos. No obstante, se ha comprobado que a pesar de estos errores los datos sobre la posición del 'mortalón' en las galerías son correctos, y las descripciones corresponden a las galerías Dornajos y EI Loro, demostrando la presencia de depósitos de 'mortalón' del deslizamiento de Micheque en ambas.

En la misma zona de Santa Úrsula se encuentra la galería Fuentenueva, visitada por los autores de este trabajo para reconocimiento de los depósitos del deslizamiento de Micheque. Su cercanía a las galerías Dornajos y El Loro permite suponer que las tres cortan al mismo depósito de 'mortalón', con seguridad las dos primeras (Fuentenueva y Dornajos, ver Figura 4). Estas tres galerías se encuentran fuera de los límites onshore inferidos por Ablay and Hurlimann (2000) para el deslizamiento East Dorsal, y la presencia de 'mortalón' en ellas indica un tamaño considerablemente mayor que el del deslizamiento por ellos inferido, extendiéndose hacia el sur hasta el valle de La Orotava. En la galería Las Breñas (situada a unos 4,5 kilómetros más al noreste) el 'mortalón' aparece a cotas y profundidades parecidas al de la galería Fuentenueva (las galerías tienen su boca a la misma cota: 435 y 440 msnm; ver Figura 4), con lo que podría también asumirse que ambos corresponden al mismo depósito. Por las anteriores evidencias, la situación y extensión del deslizamiento de Micheque bien podría corresponder a la propuesta por Carracedo et al. (2011), resultando de parecida o mayor magnitud que los otros megadeslizamientos deTenerife aquí tratados.

En la galería Las Breñas se han realizado dataciones (ver Parte I, Ferrer et al., 2020-este volumen) que indican para el deslizamiento una edad $<810 \mathrm{ka}$, en consonancia con un único dato previo en la literatura, $<830$ ka (Carracedo et al., 2009).

Un hecho a considerar es que en las galerías citadas que penetran en el relleno de Micheque, aparece un único tramo de 'mortalón', no pudiéndose por tanto proponer la ocurrencia de varios deslizamientos superpuestos.

\section{Sobre el sustrato de los deslizamientos}

Una cuestión de gran importancia en el estudio de los deslizamientos es la localización del sustrato profundo a través del cual se produjo la rotura, esto es, los materiales in situ por debajo de los planos de deslizamiento de mayor profundidad. Hasta ahora, y aunque alcanzado en varias de las galerías excavadas en los valles, solo se contaba con una datación en rocas del sustrato: la muestra GLD-20, de 2,71 Ma (Carracedo et al., 2009), al fondo de la galería Dornajos, a unos $3.000 \mathrm{~m}$ de bocamina, en la zona del deslizamiento de Micheque (Figura 4). Esta edad corresponde a una formación basáltica alterada bajo el depósito de 'mortalón', anterior al deslizamiento.

Otras dataciones realizadas en galerías (Salto del Frontón y La Gotera en el valle de Icod, y Pino Soler en La Orotava) corresponden siempre a coladas por encima de los depósitos de 'mortalón', y únicamente dos de ellas, en el valle de Icod, a rocas cercanas a su techo (Carracedo et al., 2006; Boulesteix et al., 2012 y 2013) (verTabla 1a en Ferrer et al., 2020-este volumen).

Aquí se presentan dos nuevas edades Ar/Ar obtenidas para rocas a muro de depósitos de 'mortalón', que corresponden a los materiales del sustrato o base de los deslizamientos (ver Tabla 1). Las otras dataciones realizadas por los autores en rocas a muro de depósitos de 'mortalón' (Ferrer et al., 2020-este volumen), no corresponden a los materiales del eje estructural de la Dorsal NE, que forman el sustrato profundo de los deslizamientos.

Se ha obtenido una edad de 2,55 Ma para las rocas a muro del 'mortalón' al fondo de la galería Cruz de Luis (muestra CLU-2312, a 2.300 m de bocamina, Tabla 1 y Figura 4) datando los materiales de la Dorsal no afectados por los deslizamientos de La Orotava. La diferencia con la edad de las lavas a techo de este 'mortalón' (en torno a los 500 ka) implica un gran espacio de tiempo entre los dos depósitos, que puede explicarse por un gran deslizamiento arrastrando los materiales pleistocenos del valle de La Orotava en el flanco norte de la dorsal. Carracedo et al. (2009) aportan este mismo argumento para explicar la notable diferencia de edades entre las lavas a muro $(2,71 \mathrm{Ma})$ y techo $(0,83 \mathrm{Ma})$ del 'mortalón' en la galería Dornajos, en el deslizamiento de Micheque. Los citados autores asocian la edad pliocena de 2,71 Ma a los materiales del núcleo de la Dorsal NE no afectados por el deslizamiento, que, al igual que se evidencia en la nueva datación del frente de la galería Cruz de Luis 12,55 $\mathrm{Ma})$, arrastró a los materiales pleistocenos, dejando expuestos los materiales inferiores del Plioceno. La situación y trazado de las dos galerías, y las profundidades alcanzadas en ambas (Figura 4) (ver también 
Figura 11 en Ferrer et al., 2020-este volumen,), permiten afirmar que han alcanzado el sustrato de los deslizamientos; mientras que en caso de la Orotava el deslizamiento tuvo lugar hacia los $500-530$ ka, según se deduce de las dataciones de la galería, en el caso de Micheque fue anterior a los 810-830 ka.

Carracedo et al. (2009) asocian la edad de 2,71 Ma al desarrollo de la segunda etapa de actividad eruptiva en la dorsal NE, en el Plioceno, cuyos depósitos solo han sido observados en galerías.

Otra de las nuevas dataciones aportadas en el presente trabajo, al fondo de la galería Las Breñas, que atraviesa el relleno del deslizamiento de Micheque alcanzando la cabecera del mismo (muestra LBR-5350, a $5.350 \mathrm{~m}$ de bocamina, Tabla 1), también refleja la edad de los materiales del sustrato. Corresponde a un dique a muro del depósito de 'mortalón', cortado por este, con 1,32 Ma, lo que implica una mayor antigüedad para las coladas a las que atraviesa el dique, que representan a los materiales del sustrato de este deslizamiento.

Las dataciones arriba citadas en galerías del valle de La Orotava y de Micheque son las únicas en materiales del sustrato de los deslizamientos, por debajo de los depósitos de 'mortalón' y de los planos de rotura más profundos. Otras galerías profundas, como Montaña Blanca, Chimoche o Pino Soler, en la cabecera del valle de La Orotava, visitadas por los autores, atraviesan planos de fractura y alcanzan los materiales del eje estructural de la dorsal, pero no existen dataciones, al igual que ocurre en las galerías Cueva de Las Colmenas y El Drago en la cabecera del valle de Güímar. Por lo general, en estas zonas basales los materiales aparecen con alto grado de fracturación y alteración, con fallas y fracturas verticales abiertas que se corresponden probablemente con los escarpes de rotura.

\section{Conclusiones}

Sobre la base de las nuevas dataciones realizadas, y del análisis llevado de las dataciones existentes, recogidos en la Parte I complementaria de este trabajo (Ferrer et al., 2020-este volumen), y de las observaciones en campo y en galerías llevadas a cabo, se establecen las siguientes conclusiones sobre algunos aspectos relevantes de los grandes deslizamientos de Tenerife.

\section{Sobre la ocurrencia de deslizamientos de flanco su- perpuestos}

- Se presentan nuevas evidencias y nuevas dataciones que sustentan la hipótesis de varios grandes deslizamientos superpuestos, espaciados en el tiem- po, para explicar los procesos de desmantelamiento de los flancos de la isla de Tenerife.

- Las evidencias geológicas y geomorfológicas que apuntan a la ocurrencia de varios deslizamientos sobre un mismo flanco pueden resumirse en las siguientes:

- La presencia de diferentes tramos de 'mortalón' en el interior de las galerías excavadas en los rellenos de los valles.

- Los resultados de las nuevas dataciones de los depósitos de mortalón en el interior de las galerías.

- Los rasgos morfológicos de los escarpes de cabecera de los deslizamientos, con varios lóbulos superpuestos o imbricados, y, en el caso de La Orotava, un prominente desnivel que refleja la presencia de escarpes de deslizamiento enterrados.

- La estructura de los depósitos de megatsunami atribuidos al deslizamiento de Güímar, mostrando al menos tres capas depositadas por distintos tsunamis.

- En el caso del valle de La Orotava, las dataciones aportadas en este trabajo y las existentes en la bibliografía, apoyan la ocurrencia de varios procesos de inestabilidad. Se han deducido tres deslizamientos superpuestos, con intervalos de tiempo probables de unos $30 \mathrm{ka}$.

- El primero, de mayor magnitud, sobre los $560 \mathrm{ka}$, con cabecera afectando a parte de la actual caldera de Las Cañadas, habría generado los grandes escarpes laterales del valle. Su edad queda reflejada en las dataciones existentes de los materiales de los escarpes y del relleno del valle en la pared de Las Cañadas.

- Un segundo deslizamiento, superpuesto al anterior, con edad estimada hacia los 530 ka por las nuevas dataciones realizadas en galerías; su escarpe de cabecera, reflejado en la cabecera actual del valle, puede corresponderse con los planos de fractura que aparecen al fondo de la galería Pino Soler.

- Un tercer gran deslizamiento hacia los $500 \mathrm{ka}$, en base a dataciones de galerías y a la presencia de un escalón morfológico en la zona media del vaIle, reflejo de su escarpe de cabecera, atravesado en profundidad por la galería Bolaños.

- Las edades tentativamente propuestas para los dos últimos deslizamientos se ven refrendadas por las de los depósitos turbidíticos provenientes de los deslizamientos del valle de La Orotava, en torno a los 535 y 505 ka. No se descarta la ocurrencia de otros deslizamientos menores y "locales" en el valle, como el que refleja el lóbulo que 
dibuja el escarpe de la cabecera del valle en su extremo suroeste.

- En el caso del valle de Güímar, la escasez de dataciones y la antigüedad de los deslizamientos, no permiten establecer conclusiones sobre la ocurrencia y edades de diferentes movimientos, pero pueden plantearse al menos dos grandes deslizamientos, con escarpes separados reflejados en su cabecera actual. La existencia de depósitos diferenciados de varios mega-tsunamis en la cercana costa del norte de la isla de Gran Canaria, atribuidos a este deslizamiento, apoya la propuesta de varios deslizamientos sobre este flanco SE de la isla de Tenerife.

- En el deslizamiento de Icod, la falta de evidencias en superficie y de dataciones en galerías, no permite establecer conclusiones sobre la ocurrencia de varios deslizamientos superpuestos. No obstante, las características de los depósitos submarinos proximales procedentes del deslizamiento apuntan a la ocurrencia de varios procesos, dos o tres, diferenciados en el tiempo; las dataciones existentes en la bibliografía se corresponderían con el último de ellos.

- La hipótesis de los 'múltiples deslizamientos retrogresivos' (multistage retrogressive failure) para el deslizamiento de Icod, propugnada por algunos autores en base al estudio de las turbiditas del Sistema Turbidítico Marroquí, se considera inverosímil e incompatible con los mecanismos de inestabilidad y rotura de los flancos volcánicos, con las propiedades y características mecánicas de las grandes masas rocosas, y con la profundidad de los depósitos de deslizamiento ('mortalón') bajo el valle de Icod.

\section{Sobre la relación entre el blast y el deslizamiento de Icod}

En cuanto a la relación causal entre el megadeslizamiento de Icod, el más reciente ocurrido en Tenerife y la erupción explosiva final del último ciclo del Edificio Cañadas, ambos hace unos $170 \mathrm{ka}$, las evidencias apuntan a que el deslizamiento no fue una consecuencia de la erupción, sino que éste ocurrió inmediatamente antes, como algunos autores han postulado, aunque sin pruebas concluyentes hasta ahora.

La principal evidencia la proporcionan los depósitos de megatsunami asociados a ambos procesos que aparecen en la costa norte de la isla de Tenerife, que presentan dos niveles claramente diferenciados, sin intervalo de tiempo entre ellos, cuyas características permiten atribuir el nivel basal al tsunami provocado por el deslizamiento y el nivel superior al tsunami originado por la violenta entrada en el mar de los productos del blast, o erupción explosiva lateral, que se desencadenó inmediatamente tras el deslizamiento.
Aunque en el caso de lcod ambos eventos aparecen asociados, los megadeslizamientos de flanco en islas volcánicas no tienen por qué ser desencadenados por, o estar asociados a, una gran erupción explosiva. Los principales factores que determinan las condiciones de estabilidad de los flancos son la altura y pendiente de los edificios y las propiedades físicas y mecánicas de los materiales submarinos que constituyen la base del edificio emergido y soportan su peso: las hyaloclastitas.

\section{Sobre el deslizamiento de Micheque}

El deslizamiento de Micheque, del que menos información se tiene, por no presentar ningún rasgo morfológico en superficie, se evidencia por la presencia de potentes depósitos de 'mortalón' en las galerías que atraviesan los rellenos del valle, completamente cubierto en la actualidad por sucesivas capas de coladas.

Las dataciones realizadas en el presente estudio a techo y a muro del 'mortalón' de la galería Las Breñas, y otra datación previa (Carracedo et al., 2009), permiten atribuir al deslizamiento un límite superior en torno a los 810-830 ka, coincidiendo con la edad estimada para el deslizamiento del valle de Güímar.

\section{Sobre el sustrato profundo de los deslizamientos}

En este trabajo se aportan dos nuevas dataciones en rocas a muro de sendos depósitos de 'mortalón', que representan el sustrato base de deslizamientos de La Orotava y Micheque, a través del que se desarrollaron los planos de rotura y deslizamiento. En el primer caso se ha obtenido una edad de 2,55 Ma para una colada al fondo de la galería Cruz de Luis, en los materiales de la dorsal no afectados por el deslizamiento. En el segundo caso, se ha datado un dique en un tramo intensamente alterado y fracturado, atravesado por numerosos diques antiguos, al fondo de la galería Las Breñas, resultando una edad en torno a 1,32 Ma, lo que implica una mayor antigüedad, sin poder precisar, para las coladas a las que atraviesa el dique, que representan a los materiales del sustrato del deslizamiento.

De estos datos se deduce que, en los valles de La Orotava y Micheque, los deslizamientos arrastraron a los depósitos del Pleistoceno, quedando expuestos tras la rotura los materiales más antiguos de la Cordillera Dorsal, que serían cubiertos por los propios depósitos de los deslizamientos y, posteriormente, enterrados por las coladas de relleno de los valles deslizados. 


\section{Agradecimientos}

Los datos, ideas y conclusiones que se presentan en este trabajo son resultado de más de una década de investigaciones, profundizando en algunos de los aspectos abordados en dos proyectos de investigación del Plan Nacional I+D (CGL2008-01423/BTE y CGL2004-00899) dedicados ambos al estudio de los grandes deslizamientos de flanco de la isla de Tenerife. Las dataciones y los trabajos de campo relacionados con la toma de muestras han sido financiados por proyectos propios del Instituto Geológico y Minero de España, así como todos los trabajos de laboratorio de las muestras datadas.

Los autores expresan su agradecimiento a Juan J. Coello, del Consejo Insular de Aguas de Tenerife, por su imprescindible colaboración en las investigaciones de campo y guía en las visitas a galerías; a nuestro inolvidable maestro José Manuel Navarro "el Maño" $(\dagger)$, que nos enseñó a desentrañar las claves de los deslizamientos de Tenerife; a la Dra. Julia Seisdedos, por sus trabajos de campo en las galerías de Tenerife; a nuestros colegas Dr. Cesar Andrade, Dr. José Madeira y Dra. Conceçáo Freitas, de la Universidad de Lisboa, por sus trabajos de campo sobre los tsunamis de Agaete y visitas de campo a Tenerife; y a los colegas geólogos de la Universidad de La Laguna, la Universidad de Las Palmas de Gran Canaria y la Consejería de Obras Públicas del Gobierno de Canarias, que participaron en los proyectos de investigación. Agradecemos al Dr. Luis Somoza y a otro revisor anónimo su tiempo y dedicación en la revisión del manuscrito, que sin duda ha contribuido a mejorar su contenido.

\section{Referencias}

Abdel-Monem, A., Watkins, N.D. and Gast, P. 1972. Potassium-argon ages, volcanic stratigraphy and geomagnetic polarity history of the Canary Islands: Tenerife, La Palma and Hierro. American Journal of Science, 272, 805-825.

Ablay, G.J. and Hurlimann, M. 2000. Evolution of the north flank of Tenerife by recurrent giant landslides Journal of Volcanology and Geothermal Research, 103, 135-159, doi: 10.10 [6/50377-0273(00)00220-1.

Ancochea, E., Fúster, J.M., Ibarrola, E., Cendrero, A., Coello, J., Hernán, F. et al. 1990. Volcanic evolution of the island ofTenerife (Canary Islands) in the light of new K-Ar data. Journal of Volcanology and Geothermal Research, 44, 231-249.

Ancochea, E., Huertas, M.J., Cantagrel, J.M., Coello, J., Fúster, J.M., Arnaud, N. and Ibarrola, E. 1999. Evolution of the Cañadas edifice and its implications for the origin of the Cañadas Caldera (Tenerife, Canary Islands). Journal of Volcanology and Geothermal Research, 88, 177-199.
Andrade, C., Freitas, M.C. and Madeira, J. 2010. Report of the visit to Gran Canaria to assess the origin of the Agaete chaotic marine conglomerates. Project GRANDETEN-II. Unpublished report. $11 \mathrm{pp}$.

Biain, A., León, R., Urgeles, R., Somoza, L., Medialdea, T., Ferrer, M and González, F.J. 2015. Onshore and offshore geomorphological features of the El Golfo debris avalanche (El Hierro, Canary islands). In: Lamarche et al. (Eds.), Submarine Mass Movements and their Consequences. Advances in Natural and Technological Hazards Research, 41, 83-92, doi: 10.1007/978-3-319-20979-1_8.

Boulesteix, T., Hildenbrand, A., Gillot, P.Y. and Soler, V., 2012. Eruptive response of oceanic islands to giant landslides: new insights from the geomorphologic evolution of the Teide-Pico Viejo volcanic complex (Tenerife, Canary). Geomorphology, 138, 61-73.

Boulesteix, T., Hildenbrand, A., Soler, V., Quidelleur, X. and Gillot, P.Y. 2013. Coeval giant landslides in the Canary Islands: Implications for global, regional and local triggers of giant flank collapses on oceanic volcanoes. Journal of Volcanology and Geothermal Research, 257, 90-98.

Bravo, T. 1962. El Circo de Las Cañadas y sus dependiencias. Boletín de la Real Sociedad Española de Historia Natural (Sec. Geología), 60, 93-108.

Bravo Bethencourt, J. y Bravo, T. 1989. Esquema geológico de la Pared de Las Cañadas. In: Araña y Coello (Eds.), Los volcanes y la caldera del Parque Nacional del Teide (Tenerife, Islas Canarias), 85-100, ICONA.

Brown, R.J., Barry, T.L., Branney, M.J., Pringle, M.S. and Bryan, S.E. 2003. The Quaternary pyroclastic succession of southeast Tenerife, Canary Islands: explosive eruptions, related caldera subsidence, and sector collapse. Geological Magazine, 140, 265-288.

Cantagrel, J.M., Arnaud, N.O., Ancochea, E., Fúster, J.M. and Huertas, M.J. 1999. Repeated debris avalanches on Tenerife and genesis of Las Cañadas caldera wall (Canary Islands). Geology, 27, 739-742.

Carracedo, J.C. 1994. The Canary Islands: An example of structural control on the growth of large oceanic island volcanoes. Journal of Volcanology and Geothermal Research, 60, 3/4, 225-242, doi: 10.1016/0377-0273(94)90053-1.

Carracedo, J.C., Rodríguez Badiola, E., Guillou, H., Scaillet, S., Paterne, M., Pérez-Torrado, F.J. et al. 2006. Geocronología e historia volcánica del complejo volcánico del Teide y las dorsales de Tenerife. In: Los volcanes del Parque Nacional del Teide. El Teide, Pico Viejo y las dorsales activas de Tenerife, $\mathrm{M}^{\circ}$ de Medioambiente, 69-97.

Carracedo, J.C., Rodríguez Badiola, E., Guillou, H., Paterne, M., Scaillet, S., Pérez Torrado, F.J. et al. 2007. Eruptive and structural history of Teide volcano and rift zones of Tenerife, Canary Islands. GSA Bull, 119, 9/10, 1027-1051, doi: 10.1130/B26087.1.

Carracedo, J.C., Guillou, H., Rodríguez Badiola, E., Pérez-Torrado, F.J., Rodríguez González, A., Paris, R. et al. 2009. 
La dorsal NE de Tenerife: Hacia un modelo del origen y evolución de los rifts de islas oceánicas: Estudios Geológicos, 65 (1), 5-47, doi: 10.3989/egeol.39755.056.

Carracedo, J.C., Guillou, H., Nomade, S., Rodríguez Badiola, E., Pérez-Torrado, F.J., Rodríguez González, A. et al. 2011. Evolution of ocean-island rifts: The northeast rift zone of Tenerife, Canary Islands. Geological Society of America Bulletin, 123, 3/4, 562-584; doi: 10.1130/B30119.1.

CIATF, 2019. Consejo Insular de Aguas de Tenerife. https:// ciatf.maps.arcgis.com/apps/webappviewer/index.html?i$\mathrm{d}=8 \mathrm{~d} 42 \mathrm{~d} 177780043 e 89 \mathrm{d9824cee2166995}$. Última consulta $5 / 12 / 2019$.

Coello, J. 1973. Las series volcánicas en subsuelos deTenerife. Estudios Geológicos, XXIX, 491-512.

Coello J. y Bravo, T. 1989. Correlación lito-estratigráfica de perforaciones (galerías) en la región central de Tenerife. En: Araña y Coello (Eds.), Los volcanes y la caldera del Parque Nacional del Teide (Tenerife, Islas Canarias), ICONA, 359-383.

Coello Bravo, J.J., Martín González, E. y Hernández Gutiérrez, L.E. 2014. Depósitos de tsunami originados por un deslizamiento gravitacional masivo en Tenerife (islas Canarias). Vieraea, 42, 79-102.

Edgar, C.J., Wolff, J.A., Olin, P.H., Nichols, H.J., Pittari, A., Cas, R.A.F. et al. 2007. The late Quaternary Diego-Hernandez formation, Tenerife: volcanology of a complex cycle of voluminous explosive phonolitic eruptions. Journal of Volcanology and Geothermal Research, 160, 59-85.

Elsworth, D. and Day, S. 1999. Flank collapse triggered by intrusion: the Canarian and Cape Verde Archipelagoes. Journal of Volcanology and Geothermal Research, 94, 323-340.

Felton, E.A., Crook, K.A.W. and Keating, B.H. 2000. The Hulopoe Gravel, Lanai, Hawaii: New Sedimentological Data and their Bearing on the "Giant Wave" (Mega-Tsunami) Emplacement Hypothesis. Pure and Applied Geophysics, 157, 1257-1284.

Ferrer, M., González de Vallejo, L.I. y García, J.C. 2020. Geocronología de los megadeslizamientos de Tenerife del último millón de años. Parte I: Revisión y nuevas dataciones Ar/Ar. Boletín Geológico y Minero, 131 (4), 903-940

Ferrer, M., González de Vallejo, L., González, S. and Jiménez, E. 2015. Stability and failure mechanisms of large landslides in the volcanic island flanks of the Canary Islands. In: Lollino et al. (Eds.), Engineering Geology for Society and Territory, vol. 2, Springer Int. Pub., 915-919, doi: 10.1007/978-3-319-09057-3_158. TURÍN ISBN 978-3-31909056-6.

Ferrer, M., González de Vallejo, L., Seisdedos, J., Coello, J.J., García, J.C., Hernández, L. et al. 2013. Güímar and La Orotava megalandslides (Tenerife) and tsunamis deposits in Canary Islands. In: Margottini et al. (Eds), Landslide Science and Practice, vol. 5: Complex Environment. Springer, 27-34. ROMA ISBN 978-3-642-31426-1.

Ferrer, M., Seisdedos, J. and González de Vallejo, L.I. 2010.
The role of hyaloclastite rocks in the stability of the volcanic island flanks ofTenerife. In: Volcanic Rock Mechanics, Olalla et al. (Eds), CRC Press/Balkema, 167-170. ISBN: 978-0-415-58478-4. TENERIFE

Frenz, M., Wynn, R.B., Georgiopoulou, A., Bender, V.B., Hough, G., Masson, D.G. et al. 2009. Provenance and pathways of late Quaternary turbidites in the deepwater Agadir Basin, northwest African margin. International Journal of Earth Sciences, 98 (4), 721-733.

Giachetti, T., Paris, R., Kelfoun, K. and Pérez-Torrado, F.J. 2011. Numerical modelling of the tsunami triggered by the Güímar debris avalanche, Tenerife (Canary Islands): Comparison with field-based data. Marine Geology, 284, 189-202.

Hernández Pacheco, A. y Rodríguez Losada, J.A. 1996. Geología y estructura del Arco de Taganana (Tenerife, Canarias). Revista de la Sociedad Geológica de España, 9(3-4), 169-182.

Huertas, M. J., Arnaud, N.O., Ancochea, E., Cantagrel, J.M. and Fúster, J.M. 2002. 40Ar/39Ar Stratigraphy of pyroclastic units from Cañadas Volcanic Edifice (Tenerife, Canary Islands) and their bearing on the structural evolution. Journal of Volcanology and Geothermal Research, 115, 351-365.

Hunt, J.E., Wynn, R.B., Masson, D.G., Talling, P.J. and Teagle, D.A.H. 2011. Sedimentological and geochemical evidence for multistage failure of volcanic island landslides: a case study from the Icod landslide on north Tenerife, Canary Islands. Geochemistry, Geophysics, Geosystems, 12 (12), 36 pp, doi:10.1029/2011GC003740

Hunt, J.E., Wynn R.B., Talling, P.J. and Masson, D.G. 2013 a. Turbidite record of frequency and source of large volume (>100 km3) Canary Island landslides in the last $1.5 \mathrm{Ma}$ : Implications for landslide triggers and geohazards. Geochemistry, Geophysics, Geosystems, 14 (7), 2100-2123, doi:10.1002/ggge.20139.

Hunt, J.E., Wynn R.B., Talling, P.J. and Masson, D.G. 2013b. Multistage collapse of eight western Canary Island landslides in the last 1.5 Ma: Sedimentological and geochemical evidence from subunits in submarine flow deposits. Geochemistry, Geophysics, Geosystems, 14 (7), 21592181, doi: 10.1002/ggge.20138.

Hunt, J.E., Talling, P.J., Clare, M.A., Jarvis, I. and Wynn, R.B. 2014. Long-term (17 Ma) turbidite record of the timing and frequency of large flank collapses of the Canary Islands. Geochemistry, Geophysics, Geosystems, 15, 3322-3345, doi:10.1002/2014GC005232.

Hunt, J.E., Cassidy, M. and Talling, P.J., 2018. Multi-stage volcanic island flank collapses with coeval explosive caldera-forming eruptions. Scientific Reports 8:1146, doi:10.1038/s41598-018-19285-2.

Hurlimann, M., Ledesma, A. and Marti, J. 1999. Conditions favouring catastrophic landslides on Tenerife (Canary Islands). Terra Nova, 11, 106-111. 
Ibarrola, E., Ancochea, E., Fúster, J.M., Cantagrel, J.M., CoeIlo, J., Snelling, N.J. and Huertas, M.J. 1993. Cronoestratigrafía del Macizo deTigaiga: evolución de un sector del Edificio Cañadas (Tenerife, Islas Canarias). Boletín de la Real Sociedad Española de Historia Natural (Sec. Geología), 88, 57-72.

Karstens, J., Berndt, C., Urlaub, M., Watt, S.F.L., Micallef, A., Ray, M. et al., 2019. From gradual spreading to catastrophic collapse - reconstruction of the 1888 Ritter Island volcanic sector collapse from high-resolution 3D seismic data. Earth Planetary Sciences Letters 517, 1-13.

Krastel, S., Schmincke, H.U., Jacobs, C.L., Rihm, R., Le Bas, T.P. and Alibes, B. 2001. Submarine landslides around the Canary Islands. Journal of Geophysical Research, Solid Earth, 0106 (B3), 3977-3997.

León, R., Somoza, L., Urgeles, R., Medialdea, T., Ferrer, M., Biain, A. et al. 2017. Multi-event oceanic island landslides: New onshore-offshore insights from El Hierro Island, Canary Archipelago, Marine Geology, 393, 156-175.

León, R., Palomino, D., Vázquez, J.T., Medialdea, T. and Somoza, L. 2019. A new scenario for the mass transport deposits west Canary volcanic province. Earth and Planetary Science Letters, 509, 27-37.

Madeira, J., Ferrer, M., González de Vallejo, L., Andrade, C., Freitas, M.C. and Lomoschitz, A. 2011a. Agaete revisited: new data on the Gran Canaria tsunamiites. Geophysical Research Abstracts, vol. 13, EGU2011-2292-2, 8 ${ }^{\text {th }}$ EGU General Assembly.

Madeira, J., Andrade, C. and Freitas, M.C. 2011b. Reconocimientos de campo para identificación de depósitos de tsunamis. Parte 2: Report of the visit to Tenerife to assess the origin of the chaotic marine breccias of Teno-Buenavista region. Proyecto GRANDETEN II (CGL2008-01423). Informe inédito. Centro de Documentación del IGME, Madrid. 22 pp.

Martí, J. 2019. Las Cañadas caldera, Tenerife, Canary Islands: A review, or the end of a long volcanological controversy. Earth Sciences Reviews, 196, 102889, doi:10.1016/j.earscirev.2019.102889

Martí, J., Hurlimann, M., Ablay, G.J. and Gudmundsson. A. 1997. Vertical and lateral collapses on Tenerife (Canary Islands) and other volcanic ocean islands. Geology, 25 (10), 879-882, doi:10.1130/0091-7613.

Martí, J., Mitjavila, J. and Villa, I. 1990. Stratigraphy and K-Ar ages of the Cañada de Diego Hernández and their significance on the Las Cañadas caldera formation (Tenerife, Canary Islands). Terra Nova, 2, 148-153.

Masson, D.G., Harbitz, C.B., Wynn, R.B., Pedersen, G. and Lovholt, F. 2006. Submarine landslides: processes, triggers and hazard prediction. Philosophical Transactions of the Royal Society A, 364 (1845), 2009-2039, doi: 10.1098/ rsta.2006.1810.

McMurtry, G.M., Watts, P., Fryer, G.J., Smith, J.R. and Imamura, F. 2004. Giant landslides, mega-tsunamis, and pa- leo-sea level in the Hawaiian Islands. Marine Geology, 203, 219-233.

Melian, G. 2013. Estudio geoquímico de la atmósfera del suelo en la galería Bolaños, La Orotava (Tenerife). Infore inédito. INVOLCÁN, La Laguna, Tenerife.

Mitjavila, J. and Villa, I. 1993. Temporal evolution of Diego Hernández formation (Las Cañadas, Tenerife) and confirmation of the age of the caldera using the 40Ar-39Ar method. Revista de la Sociedad Geológica de España, 6, 61-65.

Navarro, J.M. and Coello, J. 1989. Depressions originated by landslide processes in Tenerife. ESF Meeting on Canarian Volcanism, Lanzarote, 150-152.

Oehler, J.F, van Wyk de Vries, B., Labazuy, P. 2005. Landslides and spreading of oceanic hot-spot and arc-shield volcanoes on low strength layers (LSLs): an analogue modeling approach. Journal of Volcanology and Geothermal Research, 144,169-189.

Paris, R., Coello, J.J., Martín, E., Kelfoun, K. and Nauret, F. 2017. Explosive eruption, flank collapse and megatsunami at Tenerife ca. 170 ka. Nature Communications, 8, 15246 doi: 10.1038/ncomms15246.

Pérez-Torrado, F.J., Paris, R., Cabrera, M.C., Schneider, J.L., Wassmer, P., Carracedo, J.C., Rodríguez-Santana, A. and Santana, F. 2006. Tsunami deposits related to flank collapse in oceanic volcanoes: The Agaete Valley evidence, Gran Canaria, Canary Islands. Marine Geology, 227, 135149.

Pittari, A., Cas, R.A.F., Edgar, C.J., Nichols, H.J., Wolff, J.A. and Martí, J. 2006. The influence of palaeotopography on pyroclastic flow processes and facies architecture of a lithic-rich ignimbrite in a high gradient setting: the Abrigo Ignimbrite, Tenerife, Canary Islands. Journal of Volcanology and Geothermal Research, 152, 273-315.

Pittari, A., Cas, R.A.F., Wolff, J.A., Nichols, H.J., Larson, P.B. and Martí, J. 2008. The use of lithic clast distributions in pyroclastic deposits to understand pre- and syn-caldera collapse processes: A case study of the Abrigo Ignimbrite, Tenerife, Canary Islands. In: Developments in Volcanology, vol. 10, Elsevier, B.V., 97-142, doi:10.1016/S1871644X(07)00003-4.

Rubin, K.H., Fletcher, C.H. and S. Clark. 2000. Fossiliferous Lana'i deposits formed by multiple events rather than a single giant tsunami. Nature, 408, 675-681.

Satake, K. 2007. Volcanic origin of the 1741 Oshima-Oshima tsunami in the Japan Sea. Earth, Planets and Space, 59, 381-390.

Schiffman, P., Watters, R.J., Thompson, N. and Walton, A.W. 2006. Hyaloclastites and the slope stability of Hawaiian volcanoes: Insights from the Hawaiian Scientific Drilling Project's 3-km drill core. Journal of Volcanology and Geothermal Research, 151, 217-228.

Schmincke, H.U., Navarro, J.M. and Sumita, M. 1999. A giant blast associated with flank collapse of the Cañadas Volca- 
no (Tenerife, Canary Islands) 0-18 m.y. ago. In: European Union of Geosciences, EGU 10. Conference Abstract, 4, 753.

Seisdedos, J. 2009. Los grandes paleo-desplazamientos de Güimar y La Oratava (Tenerife): análisis geológico, mecanismos de inestabilidad y modelización geomecánica. Tesis doctoral. UCM. ISBN: 978-84-692-1117-5. 202 pp.

Seisdedos, J., Ferrer, M. and González de Vallejo, L.I. 2012. Geological and geomechanical models of the pre-landslide volcanic edifice of Güímar and La Orotava mega-landslides (Tenerife). Journal of Volcanology and Geothermal Research, 239-240, 92-110.

Urgeles, R., Canals, M., Baraza, J., Alonso, B. and Masson, D. 1997. The most recent megalandslides of the Canary Islands: El Golfo debris avalanche and Canary debris flow, west El Hierro Island. Journal of Geophysical Research, 102, b9, 20305-20323.

Urgeles, R., Canals, M. and Masson, D. 2001. Flank stability and processes off the western Canary Islands: a review from El Hierro and La Palma. Scientia Marina., 65 (Suppl. 1), 21-31.

Urgeles, R., Masson, D.G., Canals, M., Watts, A.B. and Le Bas, T. 1999. Recurrent large-scale landsliding on the west flank of La Palma, Canary Islands. Journal of Geophysical Research, 104, BII, 25331-25348.

Watt, S.F.L., Karstens, J., Micallef, A., Berndt, C., Urlaub, Ray, M., Desai, A. et al. 2019. From catastrophic collapse to multi-phase deposition: Flow transformation, seafloor interaction and triggered eruption following a volcanic-island landslide. Earth and Planetary Science Letters, 517, 135-147.

Watts, A.B. and Masson, D.G. 1995. A giant landslide on the north flank of Tenerife, Canary Islands. Journal of Geophysical Research, 100, 24487-24498.

Watts, A.B. and Masson, D.G. 2001. New sonar evidence for recent catastrophic collapses of the north flank of Tenerife, Canary Islands. Bulletin of Volcanology, 63, 8-19.

Weaver, P.P.E., Rothwell, R.G., Ebbing, J., Gunn, D. and Hunter, P.M., 1992. Correlation, frequency of emplacement and source directions of megaturbidites on the Madeira Abyssal Plain. Marine Geology, 109, 1-20.

Wynn, R.B. and Masson, D.G. 2003. Canary Islands Landslides and Tsunami Generation: Can we use turbidite deposits to interpret landslide processes? In: Locat et al. (Eds.), Submarine Mass Movements and Their Consequences. Advances in Natural and Technological Hazards Research, 19, 325-332. Springer.

Recibido: julio 2019

Revisado: noviembre 2019

Aceptado: enero 2020

Publicado: marzo 2021 